\title{
Article
}

\section{Droplet Microfluidics XRD Identifies Effective Nucleating Agents for Calcium Carbonate}

Levenstein, Mark A., Anduix-Canto, Clara, Kim, Yi-Yeoun, Holden, Mark, Gonzalez Nino, Carlos, Green, David C., Foster, Stephanie E., Kulak, Alexander N., Govada, Lata and Et, Al

Available at http://clok.uclan.ac.uk/29018/

Levenstein, Mark A., Anduix-Canto, Clara, Kim, Yi-Yeoun, Holden, Mark ORCID: 0000-0003-3060-7615, Gonzalez Nino, Carlos, Green, David C., Foster, Stephanie E., Kulak, Alexander N., Govada, Lata et al (2019) Droplet Microfluidics XRD Identifies Effective Nucleating Agents for Calcium Carbonate. Advanced Functional Materials, 29 (19). p. 1808172. ISSN 1616$301 X$

It is advisable to refer to the publisher's version if you intend to cite from the work. http://dx.doi.org/10.1002/adfm.201808172

For more information about UCLan's research in this area go to http://www.uclan.ac.uk/researchgroups/ and search for <name of research Group>.

For information about Research generally at UCLan please go to http://www.uclan.ac.uk/research/

All outputs in CLoK are protected by Intellectual Property Rights law, including Copyright law. Copyright, IPR and Moral Rights for the works on this site are retained by the individual authors and/or other copyright owners. Terms and conditions for use of this material are defined in the policies page. 
DOI: 10.1002/adfm.201808172

Article type: Full Paper

\section{Droplet Microfluidics XRD Identifies Effective Nucleating Agents for Calcium Carbonate}

Mark A. Levenstein, Clara Anduix-Canto, Yi-Yeoun Kim, Mark A. Holden, Carlos González Niño, David C. Green, Stephanie E. Foster, Alexander Kulak, Lata Govada, Naomi E. Chayen, Sarah J. Day, Chiu C. Tang, Britta Weinhausen, Manfred Burghammer, Nikil Kapur*, and Fiona C. Meldrum*

M. A. Levenstein, C. González Niño, Prof. N. Kapur

School of Mechanical Engineering, University of Leeds, Woodhouse Lane, Leeds LS2 9JT, United Kingdom

E-mail: N.Kapur@leeds.ac.uk

M. A. Levenstein, Dr. C. Anduix-Canto, Dr. Y.-Y. Kim, Dr. D. C. Green, S. E. Foster, Dr. A. Kulak, Prof. F. C. Meldrum

School of Chemistry, University of Leeds, Woodhouse Lane, Leeds LS2 9JT, United

Kingdom

E-mail: F.Meldrum@leeds.ac.uk

Dr. M. A. Holden

School of Physics and Astronomy, University of Leeds, Woodhouse Lane, Leeds LS2 9JT, United Kingdom

Dr. M. A. Holden

School of Earth and Environment, University of Leeds, Woodhouse Lane, Leeds LS2 9JT, United Kingdom

Dr. L. Govada, Prof. N. Chayen

Computational and Systems Medicine, Department of Surgery and Cancer, Faculty of

Medicine, Imperial College London, London SW7 2AZ, United Kingdom

Dr. S. J. Day, Prof. C. C. Tang

Diamond Light Source, Harwell Science and Innovation Campus, Didcot OX11 0DE, United

Kingdom

Dr. B. Weinhausen, Dr. M. Burghammer

European Synchrotron Radiation Facility, F-38043 Grenoble, France

Present address: Dr. C. Anduix-Canto

Alba Synchrotron Light Source, Carrer de la Llum 2-26, 08290 Cerdanyola del Vallès,

Barcelona, Spain

Present address: Dr. B. Weinhausen

European XFEL, Holzkoppel 4, 22869 Schenefeld, Germany

Keywords: droplet microfluidics, crystallization, nucleation, bioactive glass, serial crystallography, synchrotron radiation, powder X-ray diffraction

The ability to control crystallization reactions is required in a vast range of processes including the production of functional inorganic materials and pharmaceuticals and the prevention of scale. However, it is currently limited by a lack of understanding of the 


\section{WILEY-VCH}

mechanisms underlying crystal nucleation and growth. To address this challenge, it is necessary to carry out crystallization reactions in well-defined environments, and ideally to perform in situ measurements. Here, a versatile microfluidic synchrotron-based technique is presented to meet these demands. Droplet Microfluidics-Coupled X-ray Diffraction (DMC$\mathrm{XRD)}$ enables the collection of time-resolved, serial diffraction patterns from a stream of flowing droplets containing growing crystals. The droplets offer reproducible reaction environments, and radiation damage is effectively eliminated by the short residence time of each droplet in the beam. DMC-XRD is then used to identify effective particulate nucleating agents for calcium carbonate and to study their influence on the crystallization pathway. Bioactive glasses and NX illite are shown to significantly lower the induction time, highlighting the importance of both surface chemistry and topography on the nucleating efficiency of a surface. This technology is also extremely versatile, and could be used to study dynamic reactions with a wide range of synchrotron-based techniques.

\section{Introduction}

Identification of the mechanisms that govern crystallization processes promises the ability to generate crystals with specific polymorphs, morphologies and sizes, to inhibit or promote crystallization as desired, to determine when and where crystals form, and to tailor the properties of crystalline materials towards a huge range of applications. While it remains a significant technical challenge to study the dynamic, nanoscale processes that underpin crystal nucleation and growth, developments in analytical methods including electron microscopy, scanning probe microscopy and synchrotron-based techniques are now bringing this goal within reach. ${ }^{[1]}$ Recent years have therefore seen huge advances in our understanding of crystal nucleation and growth mechanisms, ${ }^{[2]}$ where it is now recognized that nucleation can be mediated by pre-nucleation species, that growth of nanoparticle 
structures can occur via the oriented aggregation of subunits, and that amorphous phases often form as precursors to crystalline phases.

To fully profit from these capabilities, it is also essential that crystallization reactions are conducted in well-defined environments that can be analyzed using a range of techniques. This can be achieved by employing small reaction volumes that overcome the problems with impurities, solution inhomogeneities and convection that occur in bulk solution, where this has traditionally been achieved using droplet levitation ${ }^{[3]}$ or by creating arrays of droplets. ${ }^{[4]}$ Thanks to the increasing accessibility of microfabrication techniques, however, microfluidic devices are now seen as a versatile alternative. With their ability to generate large numbers of identical droplets, to create defined reaction chambers, ${ }^{[5,6]}$ and to be coupled to a wide range of analytical techniques, they have been successfully used to screen reaction conditions to generate high-quality protein crystals, ${ }^{[7]}$ for nanoparticle synthesis, ${ }^{[5,8]}$ to study nucleation kinetics, ${ }^{[9]}$ and to explore polymorphism. ${ }^{[10]}$ Segmented-flow devices also provide an outstanding opportunity to carry out time-resolved analysis, where the position along the flow-channel corresponds to specific time-points in the reaction. This property can be used to study reactions with millisecond time resolution, and has been exploited to study the formation of inorganic nanoparticles that have size-dependent optical properties. ${ }^{[5,11]}$

Microfluidic devices are therefore attracting increasing attention for synchrotron-based studies of crystallization. However, with a few notable exceptions, ${ }^{[12]}$ most of the microfluidic devices used for in situ synchrotron studies have been simple in nature (e.g. restricted to short residence times, ambient temperature and pressure and simple mixing/flow configurations). To date, the principle focus of these studies has been on the characterization of protein crystals and small angle X-ray scattering (SAXS) of soft matter including liquid 


\section{WILEY-VCH}

crystals, ${ }^{[13]}$ surfactants, ${ }^{[14]}$ and biomolecules. ${ }^{[15,16]}$ Additionally, virtually all studies have been performed with continuous flow or static systems ${ }^{[15,17]}$ and analysis of flowing droplet systems has been restricted to SAXS of the formation of nanoparticles ${ }^{[18]}$ and protein assembly. ${ }^{[19,20]}$

Here, we introduce a versatile microfluidic platform for segmented-flow synchrotron X-ray studies that can accommodate a wide variety of temperatures and solvents, be designed with different channel geometries, and importantly, can be operated with long residence times such that observations can be made over minutes, rather than the seconds offered by most devices. The value of this device for studying crystallization processes is then demonstrated, where the short screening time of individual droplets ensures that the effect of the high energy X-ray beam on the reaction being studied is minimized or eliminated. Focusing on calcium carbonate precipitation, synchrotron powder X-ray diffraction (PXRD) was used to follow the evolution of the system and to identify effective nucleating agents (nucleants). While the ability to control nucleation through the simple addition of a nucleant is desirable for a huge range of applications, effective agents are as yet only known for a small number of systems, and many questions remain concerning the mechanisms by which they operate. ${ }^{[21-24]}$ Our Droplet Microfluidics-Coupled X-Ray Diffraction (DMC-XRD) technique yields precise induction times and reveals that bioactive glasses are very effective nucleants for $\mathrm{CaCO}_{3}$, where this derives from their surface chemistry rather than their porosity. The ability to perform synchrotron studies under such controlled conditions offers huge benefits for the investigation of crystallization reactions, where our strategy could be readily extended to techniques ranging from total scattering, to X-ray absorption spectroscopy (XAS) and IR Spectroscopy. 


\section{WILEY-VCH}

\section{Results}

\subsection{Design of the Microfluidic Platform}

Our goal in designing our microfluidic platform was that it should be optimized for synchrotron studies of crystallization, that it should be operable with different solvents and over a range of temperatures, and that is should be robust and reusable. These targets were met using an insert-based device (Figure 1). The interior of the device comprises a poly(tetrafluoroethylene) (PTFE) insert containing a laser-cut serpentine channel design and a T-junction droplet generator with three inlets (Figure 1c). The PTFE sheet is then sandwiched between two Kapton windows that offer low X-ray absorption, and high thermal, mechanical and chemical stability. ${ }^{[25]}$ Two additional inserts made from silicone rubber serve as fluid gaskets and protect the Kapton windows from damage when tightening the device, and the entire device is sealed together using poly(methyl methacrylate) (PMMA) base plates (Figure 1a). Both the silicone inserts and PMMA plates possess central cutouts to allow passage of Xrays, and alignment of the inserts is achieved using dowel joints located in each corner of the device (Figure 1b). The entire device can be easily disassembled and cleaned between studies, and different window or channel materials can be employed as required (Figure 1a).

\subsection{Application of Microfluidic Device in Synchrotron Studies}

The assembled device was mounted on a translational goniometer such that it could be readily moved with respect to the X-ray beam (Figure S1, Supporting Information). X-ray access to the flow channel occurs at every position where the serpentine channel crosses the central cutout (Figure 1c), and each corresponds to a specific residence time under conditions of steady flow. Time-resolved information can therefore be obtained by acquiring PXRD patterns from droplets flowing past each position (Figure 2a). These measurements were conducted using a detector frame rate greater than the frequency of passing droplets such that 


\section{WILEY-VCH}

the scattering from the aqueous droplets could be isolated from that of the continuous oil phase. ${ }^{[19]}$ This is illustrated in Figure $2 b$ in the form of 500 consecutive frames each of $20 \mathrm{~ms}$ duration, where the frames from the aqueous droplets appear darker, and those from the oil brighter. A simple algorithm implemented in MATLAB ${ }^{\circledR}$ is used to identify the frames corresponding to oil, and these are discarded. The remaining frames are then background subtracted, and finally, all of the diffraction data at a specific location is combined into a single composite diffraction pattern (Figure 2c). A more detailed description of the processing routine and a copy of the MATLAB code are included with the supporting information.

\subsection{Detection Limit}

The detection limit of DMC-XRD was estimated by recording PXRD patterns from droplets containing nanoparticles (NPs) of known size and composition, and determining the NP concentration at which diffraction spots could no longer be recorded. $12 \mathrm{~nm}$ magnetite $\left(\mathrm{Fe}_{3} \mathrm{O}_{4}\right)$ and $15 \mathrm{~nm}$ gold NPs were analyzed, and were detectable at $\approx 0.31 \mathrm{wt} \%$ and $\approx 0.05$ wt\%, respectively (Figure 3 and Figure S2, Supporting Information), where the greater sensitivity to gold derives from its higher electron density and larger size. The detection of gold NPs down to $0.05 \mathrm{wt} \%$ places DMC-XRD within the same sensitivity range as second harmonic generation (SHG) microscopy-guided PXRD, which can detect crystalline materials down to 100 ppm by mass, or $0.01 \mathrm{wt} \% .^{[26]}$

Based on these measurements, we estimate the necessary contrast, or signal-to-noise ratio required to perform DMC-XRD. The main Bragg reflections of both gold and magnetite could no longer be detected once they fell below the baseline intensity (caused by background scattering from the solution and device windows) of the order of $10^{4}$ arbitrary 


\section{WILEY-VCH}

units (Figure 3c). These plots were made from composite diffraction patterns of 500 frames, $\approx 115-188$ of which are from the droplets based on the volume fractions of the dispersed phase utilized to obtain the various dilutions. This amounts to a baseline noise of $\approx 53-85$ arbitrary units per frame, where this will vary based on solution composition, window material, scattering angle and processing parameters. To put this into perspective, at ESRF beamline ID13, a single pixel of a single diffraction spot from a calcite (104) reflection is typically in the order of $10^{2}$ to $10^{3}$ arbitrary units (Figure S3, Supporting Information).

\subsection{Calcium Carbonate Precipitation in Droplets}

The insert-based device was operated using a Cetoni neMESYS syringe pump equipped with four low-pressure dosing modules, and Milli-Q water, $\mathrm{CaCl}_{2}$ and $\mathrm{Na}_{2} \mathrm{CO}_{3}$ solutions and Fluorinert FC-40 oil containing triblock co-polymer surfactant ${ }^{[27]}$ were loaded into four syringes. When nucleants were employed these were mixed with the $\mathrm{CaCl}_{2}$ solutions, and constant agitation was maintained using a stirrer module to ensure homogenous dispersal of the nucleants. Calcium carbonate was precipitated by combining the water, $\mathrm{CaCl}_{2}$ and $\mathrm{Na}_{2} \mathrm{CO}_{3}$ solutions and dispersing them in the $\mathrm{FC}-40$ at the required volume fraction to produce water-in-oil (w/o) droplets with compositions of $50 \mathrm{mM} \mathrm{Ca}^{2+} / \mathrm{CO}_{3}{ }^{2-}$. The water flow was positioned between the $\mathrm{CaCl}_{2}$ and $\mathrm{Na}_{2} \mathrm{CO}_{3}$ flows and acts as a buffer to delay mixing away from the junction until the droplets are formed (Figure 1c, inset); this is effective in preventing fouling. Amorphous calcium carbonate (ACC) is the first phase precipitated under these conditions, and transformation to crystalline polymorphs occurs with time.

\subsection{Selection of Nucleants}

Potential nucleants were chosen from a pool of materials often investigated for protein and ice nucleation, as most prior work on heterogeneous nucleating agents has been focused in 


\section{WILEY-VCH}

these areas. Non-porous (type 45S5) and porous (type 58S) bioactive glasses (BG), unfunctionalized and carboxylate-functionalized controlled pore glasses (CPG), and the minerals kaolinite, NX illite, amazonite and montmorillonite were initially selected, where these exhibit a range of surface chemistries and porosities. As many naturally-occurring minerals are supplied with $\mathrm{CaCO}_{3}$ contamination, all mineral samples were washed with acid prior to use (see Experimental section). Bioactive glasses are recognized to promote the formation of hydroxyapatite, ${ }^{[28]}$ where mesoporous varieties can additionally serve as effective nucleants for proteins. ${ }^{[21]} \mathrm{CPGs}$ are also mesoporous, but consist primarily of $\mathrm{SiO}_{2}$ and can be functionalized with self-assembled monolayers (SAMs). The mineral samples were selected as they are well-characterized atmospheric aerosols which can promote ice nucleation. ${ }^{[29]}$ Preliminary trials with $0.025 \mathrm{wt} \%$ dispersions of the mineral powders in $2 \mu \mathrm{L}$ droplets of $50 \mathrm{mM}$ calcium carbonate solutions on hydrophobic petri dishes were conducted to select the best mineral for further analysis (Figure S4, Supporting Information). This initial screening process revealed that NX illite was the only mineral studied which significantly promoted $\mathrm{CaCO}_{3}$ crystallization, and thus $\mathrm{NX}$ illite was the only mineral selected for further investigation using DMC-XRD.

All nucleants selected for DMC-XRD analysis were characterized to compare properties including size and surface area (Table 1). ${ }^{[30,31]}$ Scanning electron microscopy (SEM) revealed that all of the nucleant particles ranged in size from hundreds of nanometers to several microns (Figures 4a-4d), and confirmed the regular porous surface of the CPGs and the irregular void-filled surfaces of the NX illite and porous BG. The pore volume and pore size distribution of the porous BG, CPG and NX illite particles were determined by Brunauer-Emmett-Teller (BET) and Barrett-Joyner-Halenda (BJH) analysis of $\mathrm{N}_{2}$ gas desorption measurements (Figure 4e). The porous BG and the CPGs exhibit pores with 


\section{WILEY-VCH}

diameters in the range 6-21 nm and 3-11 nm, respectively. The NX illite had a few pores in this range, but the majority were greater than $20 \mathrm{~nm}$ in size. The porous BG had a specific surface area of $\approx 180$ times greater than its non-porous counterpart.

\subsection{DMC-XRD of Nucleant-Mediated CaCO3 Crystallization}

DMC-XRD was used to study $\mathrm{CaCO}_{3}$ crystallization in the presence of the five selected nucleants, and the results were compared to the effects of $50 \mathrm{~nm}$ calcite nanoparticle seeds (Figure S5, Supporting Information) and additive-free control conditions. The nucleants were introduced as a suspension in the calcium solution at $0.01 \mathrm{wt} \%$ and XRD patterns were recorded at different positions (and thus reaction times) on the device. Induction times ( $\mathrm{t}_{\text {ind }}$ ) were identified as the position on the device where diffraction was first observed. These varied considerably, where the shortest was $\leq 4.23 \mathrm{sec}$ for the experiments with the calcite seeds. The porous BG was almost as effective as the calcite seeds ( $t_{\text {ind }} \leq 12.15 \mathrm{sec}$ ), while NX illite $\left(\mathrm{t}_{\text {ind }} \leq 16.00 \mathrm{sec}\right)$ and the non-porous BG $\left(\mathrm{t}_{\text {ind }} \leq 40.77 \mathrm{sec}\right)$ were also highly active. Both of the CPG samples and the control conditions exhibited induction times longer than the 142 sec residence time of the device.

Induction times exceeding the residence times of the device were evaluated by halting the flows to incubate the droplets on-chip, and characterizing the droplets with polarized light optical microscopy. In the control experiment without nucleants, many droplets still did not contain crystals until after $30 \mathrm{~min}$ (Figure 5a). After 2-5 min, some droplets containing CPGs and carboxylated CPGs contained one or two crystals in addition to ACC (Figure 5b). By comparison, immediately after flow stoppage, droplets containing calcite seeds or porous BG contained over fifty crystals several microns in size and no ACC (Figures 5c and 5d). At the same time-point, those droplets containing NX illite and the non-porous BG contained 


\section{WILEY-VCH}

between two and ten crystals, together with some residual ACC (Figures 5e and 5f). Lower magnification images from each case can be found in Figure S6, Supporting Information.

The diffraction patterns recorded (Figure 6 and Figure S7, Supporting Information) were also consistent with these results, where partial diffraction collected from as few as 15 droplets over $10 \mathrm{sec}$ (Figure $2 \mathrm{~b}$ and $2 \mathrm{c}$ ) could be combined to produce complete diffraction patterns containing all reflections. Rapid increases in peak height and the number of detectable peaks were observed with time for the calcite seeds and porous BG. The NX illite and non-porous BG also show growth in peak intensities, but slower than that observed for the calcite seeds or porous BG. The CPG and control experiments only exhibit random diffraction events, where these may arise from crystals that managed to grow on the device surfaces. All the diffraction patterns collected matched those of calcite, with the exception of some traces of aragonite in the presence of NX illite (Figure 6c and Figure S8, Supporting Information). The diffraction data were also integrated to compare the relative amount of material present at each time point. After initial detection of crystals, the integrated intensity from the seeded and porous BG experiments grew exponentially and then subsequently settled to near a constant value (Figure 7). Slower growth could be observed in the non-porous BG and NX illite runs (Figure 7), and no consistent growth pattern emerged from the CPG or unseeded experiments (Figure S9e-g, Supporting Information).

\subsection{Crystallization Mechanisms}

Further insight into the transformation of $\mathrm{ACC}$ to crystalline $\mathrm{CaCO}_{3}$ was obtained using optical microscopy to monitor crystallization in droplets formed within transparent polydimethylsiloxane (PDMS) microfluidic devices. Imaging using polarizers that are set at nearly $90^{\circ}$ to each other enables any crystalline particles to be readily observed. A typical 


\section{WILEY-VCH}

experiment with a good nucleant (here calcite nanoparticles) is shown in Movie 1, Supporting Information, where droplets initially appear dark and then present bright birefringent crystals towards the end of the device. Immediate precipitation of ACC occurs after droplet formation, resulting in a turbid solution (Movie 2, Supporting Information). The ACC then aggregates to form large masses that are present at the highest concentration near the droplet tail (Figure 5a). These subsequently break-up as crystals nucleate and grow, leading to a more homogenous dispersal of material within the droplets. Finally, the droplets become less turbid as the crystals grow at the expense of the ACC. In the control experiment, or experiments with poor nucleants, no apparent depletion of ACC or crystal growth was observed within the residence time of the chip. SEM images of material collected at the device outlet can be found in Figure S10, Supporting Information. Material from the calcite nanoparticle-seeded and porous BG experiments consisted of primarily $<10 \mu \mathrm{m}$ calcite crystals. Crystals collected from the NX illite and non-porous BG experiments were mainly calcite of $>10 \mu \mathrm{m}$ size. Droplets from the CPG and unseeded control experiments also contained some large $>10 \mu \mathrm{m}$ calcite crystals, but comprised a larger amount of spherical vaterite crystals (Figure S10, Supporting Information). ${ }^{[32]}$

\section{Discussion}

While classical nucleation theory suggests that heterogeneous nucleation should proceed more readily on virtually all surfaces as compared with homogeneous nucleation, practical experience shows that it is actually rather difficult to identify exceptional nucleants. For calcium carbonate, many studies of heterogeneous nucleation have originated from the field of biomineralization, where these have demonstrated that organic matrices can direct the locations, orientations and even polymorphs of crystals. ${ }^{[33]}$ Although nucleation rates are seldom recorded, one study showed that nucleation rates are substrate-specific and the 
thermodynamic barrier to nucleation is reduced by minimizing the interfacial free energy of the system. ${ }^{[34]}$

The vast majority of work on nucleating agents has instead been conducted with ice and proteins, and has suggested that nucleants can promote nucleation by a range of mechanisms. ${ }^{[22,35,36]}$ (1) If the crystal/nucleant interfacial energy is less than the crystal/solution interfacial energy, nucleation is favored on the surface of the nucleant due to the reduction in the solution/nucleus interfacial area and, therefore, the reduction in the total interfacial energy. (2) The surface of the nucleant may adsorb ions/molecules from the solution, locally increasing supersaturation. (3) The nucleant may adsorb and align solute molecules, which could assist in nucleation. (4) The nucleant may allow for the formation of different nuclei/ polymorphs, which are more stable, faster growing or have smaller critical radii. (5) Nucleants may exhibit surface defects that act to concentrate or organize the component ions, thus promoting nucleation.

Of the nucleants investigated, the porous bioactive glass was the most effective in reducing the induction time ( $\mathrm{t}_{\text {ind }} \leq 12.15 \mathrm{sec}$ ) and increasing the growth rate. Our data therefore show that bioactive glasses can influence crystallization on extremely short time-scales, in contrast to the hours and days typically employed in in vitro bone growth assays. ${ }^{[37]}$ The activities of these materials as protein nucleants have been ascribed to their porous structures, where proteins concentrate within the pores, and the pore can stabilize the forming nucleus. ${ }^{[36]}$ Our experiments clearly show that this is not the case for $\mathrm{CaCO}_{3}$, where both unmodified and carboxylate-functionalized CPGs with comparable pore sizes to the porous BG do not act as effective nucleants. Furthermore, the non-porous BG also effectively nucleated calcite ( $\mathrm{t}_{\text {ind }} \leq$ $40.77 \mathrm{sec}$ ), which suggests that the nucleating capability of bioactive glasses derives from 


\section{WILEY-VCH}

their surface chemistry rather than their porosity. Both bioactive glass samples have similar compositions, where they both contain $\mathrm{SiO}_{2}, \mathrm{CaO}$, and $\mathrm{P}_{2} \mathrm{O}_{5}$ and the non-porous $\mathrm{BG}$ additionally contains some $\mathrm{Na}_{2} \mathrm{O}$ (Table 1 ). An important lesson from the ice nucleation literature is to compare nucleants based on their surface area in addition to their mass. ${ }^{[22]}$ Indeed, while the non-porous $\mathrm{BG}$ did not nucleate crystalline $\mathrm{CaCO}_{3}$ as well as its porous counterpart in our primary experiments at equal mass percent (Figures 5d, 5f, 6b, 6d and 7), subsequent experiments with equalized surface area showed that they both can crystallize calcite from ACC with similar efficiency (Figure S11, Supporting Information).

Bioactive glasses are employed in vivo as they facilitate the growth of a surface hydroxycarbonate apatite (HCA) layer that can bond to and integrate with existing hard tissue. ${ }^{[28]}$ The HCA layer forms due to cation exchange with the solution, partial dissolution of the silicate network, formation and successive condensation of silanol ( $\mathrm{Si}-\mathrm{OH})$ groups into a silica-rich gel layer, and finally the creation and subsequent crystallization of a carbonaterich amorphous calcium phosphate (ACP) layer into HCA. ${ }^{[38]}$ It has also been reported that calcite can form on these bioactive glasses ${ }^{[39]}$ at high bioactive glass loadings that rapidly deplete phosphate ions and increase the concentration of calcium ions in the solution. ${ }^{[40]}$

The activity of bioactive glass in promoting $\mathrm{CaCO}_{3}$ formation therefore also likely derives from the unique chemical environment that forms at its surface. Notably, this is created immediately when the bioactive glass is immersed in the crystallization solution, as shown from estimates of the induction times using time-resolved turbidity measurements and polarized light microscopy (Figures S12 and S13, Supporting Information). Comparable induction times were recorded for porous BG that had been incubated in water for one day prior to the analysis, and porous BG that was freshly immersed in the solution. We therefore 


\section{WILEY-VCH}

suggest dissolution of the surface of bioactive glass leads to the formation of an amorphous, calcium- and carbonate-rich layer, which facilitates calcite nucleation.

Our study also demonstrates that $\mathrm{NX}$ illite is an effective nucleant for $\mathrm{CaCO}_{3}$. $\mathrm{NX}$ illite is a heterogeneous material made from a variety of minerals, including kaolinite, feldspar and illite, and is considered a good proxy for natural dust ${ }^{[22]}$ (Table 1). Previous studies of the influence of kaolinite and montmorillonite ${ }^{[41]}$ and quartz ${ }^{[41,42]}$ on calcium carbonate nucleation suggested that, of these, only montmorillonite was effective, where this was attributed to a structural match between $\mathrm{CaCO}_{3}$ and the mineral. In contrast, the results presented here did not show montmorillonite to be an effective nucleant. However, the previous study was conducted under different ionic conditions and with uncleaned montmorillonite, which may account for the discrepancy. This also suggests the ability of montmorillonite to nucleate calcite is not due to structural matching alone. Again, it is the field of ice nucleation which has looked in most detail at the properties of individual mineral samples, where it was shown that of the mineral dusts examined, only alkali feldspars with nanoscale topographical features related to K- and Na-rich domains show exceptional icenucleating abilities. ${ }^{[4,43]}$ That topographical features such as pits and cracks promote ice nucleation has been seen in a range of experimental studies, ${ }^{[24,44,45,46]}$ and is also consistent with the formation of protein crystals on contaminants such as dust particles, fibers or hairs. ${ }^{[47]}$

These results therefore further highlight the challenges in identifying effective nucleating agents, where their activities can be very system-specific. While a low interfacial energy between the nucleant and new crystal phase will undoubtedly promote heterogeneous nucleation, this can be hard to predict, especially as real surfaces are seldom pristine. Indeed, 
many crystals with good lattice matches to ice are ineffective nucleants, ${ }^{[48]}$ while crystalline steroids can effectively nucleate ice, despite no obvious structural relationship. ${ }^{[44]}$ The potential role of surface topography in promoting nucleation is also attracting increasing recognition, ${ }^{[4,36,46,49]}$ but offers a considerable challenge to study experimentally; it is extremely difficult to identify and characterize the precise site of nucleation, where this may often be part of a larger-scale structure. The methods presented here therefore offer a highly valuable means of evaluating a nucleant's efficiency, where this ultimately enables us to build a comprehensive understanding of the mechanisms by which they operate.

\section{Conclusion}

In summary, we have described a versatile and re-usable microfluidic platform that is ideally suited to the study of crystallization processes using synchrotron X-ray techniques. In addition to enabling precise correlation between channel position and residence time, the use of segmented-flow conditions minimizes the problems with surfaces, convection and impurities that occur in bulk solution, and allows hundreds to thousands of identical droplets to be analyzed per experiment to gain information from a large sample population without the effects of beam damage. Droplet Microfluidics-Coupled PXRD (DMC-XRD) was used to identify effective nucleating agents for calcium carbonate, and was shown to deliver quantitative information such as induction times and crystallographic parameters, with a sensitivity to crystalline material down to ppm quantities. Our results demonstrate that bioactive glass and NX illite are effective nucleants for calcite, implicating the importance of both surface chemistry and topography in the design of nucleating agents. This technique and the insert-based microfluidic platform have application in a variety of scientific disciplines and will enable a wide range of synchrotron X-ray studies of dynamic processes. 


\section{WILEY-VCH}

\section{Experimental Section}

Preparation of Nucleants: The 58S porous bioactive glass was obtained from Molecular Dimensions (Naomi's Nucleants), and the 45S5 non-porous bioactive glass was obtained from XL Sci-Tech. The controlled porous glass was obtained from Schott (CoralPor $\left.{ }^{\circledR} 1000\right)$, and the NX illite was obtained from B + M Nottenkämper (Arginotec ${ }^{\circledR}$ NX). The kaolinite $\left(\mathrm{Al}_{4}(\mathrm{OH})_{8} \mathrm{Si}_{4} \mathrm{O}_{10}\right)$ and montmorillonite $\left((\mathrm{Na}, \mathrm{Ca})_{0.33}(\mathrm{Al}, \mathrm{Mg})_{2}\left(\mathrm{Si}_{4} \mathrm{O}_{10}\right)(\mathrm{OH})_{2} \cdot \mathrm{nH}_{2} \mathrm{O}\right)$ were obtained from the Clay Mineral Society (Kaolinite KGa-1b and Montmorillonite SWy-2, respectively), which makes untreated mineral samples available for research usage. The amazonite was obtained from the University of Leeds mineral collection, where its identification as an alkali feldspar was confirmed by PXRD and Raman Spectroscopy. Before being used for experiments or characterization, nucleants were freshly ground with a mortar and pestle. Additionally, the mineral nucleants were cleaned to remove possible organic contamination and any inorganic salts (principally calcite). To remove organics, the mineral powders were placed in a $3 \% \mathrm{NaClO}$ solution overnight with constant shaking. They were then sonicated, centrifuged with supernatant removed, and filled with fresh DI water 3 times, and finally washed with ethanol and dried in the oven at $60{ }^{\circ} \mathrm{C}$ overnight. To remove calcite, the powders were sonicated in a $1 \% \mathrm{HCl}$ solution at $\mathrm{pH}=4$ for $10 \mathrm{~min}$. They were then centrifuged, washed with ethanol and water, and dried as before.

The carboxyl-functionalized CPGs were prepared using a chemical vapor deposition method modified from Le Caer et al. ${ }^{[50]}$ Briefly, $1 \mathrm{~mL}$ of 3-aminopropyl-triethoxysilane was placed in a vacuum chamber with the CPG sample for 1 hour at room temperature. The silane was then removed from the chamber and the vacuum was reapplied, this time at $45^{\circ} \mathrm{C}$ for $1 \mathrm{~h}$, to evaporate excess silane from the pores. Following this, the CPGs were rinsed with toluene and ethanol, respectively, and placed in an oven at $60{ }^{\circ} \mathrm{C}$ for $2 \mathrm{~h}$ for drying. The deposited 


\section{WILEY-VCH}

amine-terminated groups were then converted to carboxyl groups by leaving them in a $10 \%$ succinic anhydride and 1\% 4-dimethyl(amino)pyridine solution of N,N-dimethylformamide (DMF) overnight. ${ }^{[51]}$ Finally, the CPGs were washed with DMF, water and ethanol, respectively, and dried at $60^{\circ} \mathrm{C}$ for $2 \mathrm{~h}$.

Before experiments, $0.1 \mathrm{wt} \%$ solutions of each nucleant were made in water. These stock solutions were used to prepare $\mathrm{CaCl}_{2}$ solutions which comprised a final nucleant concentration of $0.01 \mathrm{wt} \%$. The nucleant-containing $\mathrm{CaCl}_{2}$ solutions were sonicated for $5 \mathrm{~min}$ immediately prior to use in microfluidic experiments.

Characterization of Nucleants: The nucleants were characterized using scanning electron microscopy (SEM) and $\mathrm{N}_{2}$ adsorption/desorption for Brunauer-Emmett-Teller (BET) surface area analysis and Barrett-Joyner-Halenda $(\mathrm{BJH})$ pore size distribution. For SEM analysis, nucleants were transferred onto silicon substrates and mounted on aluminum stubs with copper tape. Analysis was conducted on uncoated samples using the circular backscatter (CBS) detector of a Nova NanoSEM 450 (FEI) at $5.00 \mathrm{kV}$. The NX Illite samples were coated with a $2 \mathrm{~nm}$ layer of iridium and imaged with a through-the-lens detector (TLD). BET analysis was performed with an ASAP 2020 Plus system (Micrometrics), where the pore size distributions were determined from the $\mathrm{BJH}$ model of $\mathrm{N}_{2}$ desorption.

Crystallization of Calcium Carbonate in Microfluidic Devices: $\mathrm{CaCl}_{2}$ solutions were prepared by first making a $1 \mathrm{M}$ solution $(1.470 \mathrm{~g}$ in $10 \mathrm{~mL}$ of water), then subsequently mixing $1.5 \mathrm{~mL}$ of this solution with $0.5 \mathrm{~mL}$ of a $0.1 \% \mathrm{w} / \mathrm{w}$ nucleant solution and $3 \mathrm{~mL}$ of water to make 5 $\mathrm{mL}$ of $300 \mathrm{mM} \mathrm{CaCl} 2$ with $0.01 \%$ w/w nucleant. $\mathrm{Na}_{2} \mathrm{CO}_{3}$ solutions were prepared freshly each day by dissolving $0.318 \mathrm{~g}$ in $10 \mathrm{~mL}$ of water to give a concentration of $300 \mathrm{mM}$. Both 


\section{WILEY-VCH}

solutions were filtered with a $0.22 \mu \mathrm{m}$ membrane (Millipore), with the original $1 \mathrm{M} \mathrm{CaCl}_{2}$ being filtered before the preparation of the $300 \mathrm{mM} \mathrm{CaCl}_{2}$ solution with added nucleants. The $\mathrm{Na}_{2} \mathrm{CO}_{3}$ solution, DI water, and FC-40 with $2.0 \%$ w/w PFPE-PEG block-copolymer surfactant $^{[27]}$ were loaded into $2 \mathrm{~mL}$ syringes (BD Plastipak) and mounted on low-pressure pumping modules (neMESYS, Cetoni). The nucleant-containing $\mathrm{CaCl}_{2}$ solution was loaded into a $5 \mathrm{~mL}$ glass syringe (ILS) containing a magnetic stirrer bar and mounted onto the neMESYS pump with the neMIX attachment to ensure uniform dispensing of the nucleants throughout the experiment.

In experiments with PDMS devices, syringes were connected to $1 \mathrm{~mm}$ punched inlet/outlet holes in the devices using $1.09 \mathrm{~mm}$ OD polyethylene tubing (Smith Medical). In experiments with insert-based devices, the syringes were connected to the device using 1/16" OD FEP tubing and flangeless $1 / 4-28$ HPLC fittings (IDEX). The FC-40 solution was pumped into the device first, in order to wet the channel walls, and then the DI water was introduced.

Subsequently, all the solutions were pumped into the device for a total flow rate ratio of 20:2:8:2 or 20:1:4:1 $\mu \mathrm{L} \mathrm{min}{ }^{-1} \mathrm{FC}-40: \mathrm{CaCl}_{2}: \mathrm{DI}: \mathrm{Na}_{2} \mathrm{CO}_{3}$ which resulted in a final $\mathrm{Ca}^{2+} / \mathrm{CO}_{3}{ }^{2-}$ ion concentration of $50 \mathrm{mM}$ and a final nucleant concentration of $0.0017 \% \mathrm{w} / \mathrm{w}$ in each droplet. The DI water was introduced between the two reagents at the T-junction to delay mixing until droplets were produced. Subsequent to mixing, $\mathrm{CaCO}_{3}$ precipitated in the supersaturated droplets during transit along the flow channel. The residence time at each viewing position was determined by calculating the mean velocity, $v_{\text {mean }}=Q_{\text {total }} / A$, where $Q_{\text {total }}$ is the combined volumetric flow rate $\left(\mu \mathrm{m}^{3} \mathrm{~s}^{-1}\right)$ set on the pumps and $A$ is the crosssectional area of the channel $\left(\mu \mathrm{m}^{2}\right)$. 


\section{WILEY-VCH}

Detection Limit Measurements: FC-40 with 2.0\% w/w PFPE-PEG block-copolymer surfactant,${ }^{[27]}$ DI water, and an aqueous suspension of pre-made nanoparticles were introduced to the device in the same fashion as in crystallization experiments, however the third aqueous inlet was closed with a $1 / 4-28$ PTFE plug. The nanoparticle suspension and the DI water were mixed at the T-junction and broken up into droplets by the FC-40 at a total flow rate ratio of 20:6 $\mu \mathrm{L} \mathrm{min}{ }^{-1} \mathrm{FC}-40$ :aqueous. The ratio of water to nanoparticle solution flow rate was varied (always equaling a total of $6 \mu \mathrm{L} \mathrm{min}^{-1}$ ) to obtain the different nanoparticle concentrations within the droplets. Diffraction data was collected from the first channel position. Nanoparticle suspensions were sonicated for 5 min immediately before being loaded into syringes.

Optical and Polarized Light Microscopy: Crystallization in PDMS devices was observed using a Leica M165 FC stereo microscope in bright field transmission mode. Images and videos were recorded using a USB 3.0 Leica DMC2900 color camera with a 3.1 Megapixel CMOS sensor using the Leica Application Suite (LAS) software. Polarized images and videos were obtained by orienting the analyzer above the sample at close to $90^{\circ}$ to the polarizer below the sample.

Droplet Microfluidics-Coupled X-Ray Diffraction Analysis: Time-resolved XRD analysis at ESRF beamline ID13 (Microfocus) was performed with an X-ray beam of $13 \mathrm{keV}$ and 12 (V) $\mathrm{x} 15(\mathrm{H}) \mu \mathrm{m}^{2}$ spot size using an EigerX $4 \mathrm{M}$ detector at $116 \mathrm{~mm}$ sample-to-detector distance. Devices were mounted on a computer-controlled XYZ stage, where alignment and positioning were facilitated with an inline optical microscope. After the coordinates of each analysis position were determined, the source flows were switched on and allowed to equilibrate. Then 10-20 second exposures were collected at each position at 50 frames-per- 
second (fps). All synchrotron XRD data presented here were collected at ID13, with the exception of the non-porous bioactive glass datasets.

DMC-XRD of non-porous bioactive glass-mediated $\mathrm{CaCO}_{3}$ crystallization was performed at Diamond beamline I22 (Small Angle Scattering \& Diffraction) with an X-ray beam of 12.4 $\mathrm{keV}$ and $80(\mathrm{~V}) \times 320(\mathrm{H}) \mu^{2}$ spot size using a Pilatus $2 \mathrm{M}$ detector at $164 \mathrm{~mm}$ sample-todetector distance. Similarly, devices were mounted on a translational goniometer, and the analysis positions were refined by scanning in both directions perpendicular to the beam and finding the location of maximum photon transmission. After flow equilibration, data were collected from each position at 100 fps over 20 second exposures.

\section{Supporting Information}

Supporting Information is available from the Wiley Online Library or from the author. Data that support the findings of this study are available in the Research Data Leeds Repository with the identifier https://doi.org/10.5518/472.

\section{Acknowledgements}

This work was supported by a UK Engineering and Physical Sciences Research Council (EPSRC) Platform Grant (EP/N002423/1) and received funding from the European Research Council (ERC) under the project DYNAMIN - DLV-788968. M.A.H. and F.C.M. were additionally supported by EPSRC grant EP/M003027/1. The authors acknowledge the European Synchrotron Radiation Facility for time on beamline ID13 under proposals CH4555, CH4928 and CH5267 and thank beamline scientist Michael Sztucki for assistance. The authors also thank Diego Pontoni, Peter van der Linden, and Pierre Lloria for support from the Partnership for Soft Condensed Matter (PSCM) during ESRF beamtimes. We also acknowledge Diamond Light Source for access to beamline I11 (EE10425 and EE12352) and beamline I22 (SM17729) for additional data collection and thank beamline scientists Andrew Smith, Tim Snow, and Nick Terrill for assistance. The authors thank Graham Brown and Andrew Pickering of the EPSRC National Facility for Innovative Robotic Systems for device fabrication services. M.A.L. acknowledges support from the US-UK Fulbright Commission and the Leeds International Research Scholarship.

Received: ((will be filled in by the editorial staff))

Revised: ((will be filled in by the editorial staff)) Published online: ((will be filled in by the editorial staff)) 


\section{WILEY-VCH}

\section{References}

[1] P. J. M. Smeets, A. R. Finney, W. Habraken, F. Nudelman, H. Friedrich, J. Laven, J. J. De Yoreo, P. M. Rodger, N. Sommerdijk, Proc. Natl. Acad. Sci. U. S. A. 2017, 114, E7882; A. E. S. Van Driessche, N. Van Gerven, P. H. H. Bomans, R. R. M. Joosten, H. Friedrich, D. Gil-Carton, N. Sommerdijk, M. Sleutel, Nature 2018, 556, 89; X. Ma, S. Zhang, F. Jiao, C. J. Newcomb, Y. L. Zhang, A. Prakash, Z. H. Liao, M. D. Baer, C. J. Mundy, J. Pfaendtner, A. Noy, C. L. Chen, J. J. De Yoreo, Nat. Mater. 2017, 16, 767; F. Bertolotti, D. Moscheni, A. Guagliardi, N. Masciocchi, Eur. J. Inorg. Chem. 2018, 3789; D. Koziej, Chem. Mater. 2016, 28, 2478; S. F. Tan, S. W. Chee, G. H. Lin, U. Mirsaidov, Acc. Chem. Res. 2017, 50, 1303; T. Yamazaki, Y. Kimura, P. G. Vekilov, E. Furukawa, M. Shirai, H. Matsumoto, A. E. S. Van Driessche, K. Tsukamoto, Proc. Natl. Acad. Sci. U. S. A. 2017, 114, 2154; M. L. Whittaker, P. J. M. Smeets, H. Asayesh-Ardakani, R. Shahbazian-Yassar, D. Joester, Angew. Chem. Int. Ed. 2017, 56, 16028.

[2] J. J. De Yoreo, P. Gilbert, N. Sommerdijk, R. L. Penn, S. Whitelam, D. Joester, H. Z. Zhang, J. D. Rimer, A. Navrotsky, J. F. Banfield, A. F. Wallace, F. M. Michel, F. C.

Meldrum, H. Colfen, P. M. Dove, Science 2015, 349, aaa6760; B. R. Chen, W. H. Sun, D. A. Kitchaev, J. S. Mangum, V. Thampy, L. M. Garten, D. S. Ginley, B. P. Gorman, K. H. Stone, G. Ceder, M. F. Toney, L. T. Schelhas, Nat. Commun. 2018, 9, 9.

[3] S. Lee, H. S. Wi, W. Jo, Y. C. Cho, H. H. Lee, S. Y. Jeong, Y. I. Kim, G. W. Lee, Proc. Natl. Acad. Sci. U. S. A. 2016, 113, 13618; T. Y. Nguyen, E. A. Roessler, K. Rademann, F. Emmerling, Z. Krist.-Cryst. Mater. 2017, 232, 15; D. Selzer, N. Tullmann, A. Kiselev, T. Leisner, M. Kind, Cryst. Growth Des. 2018, 18, 4896.

[4] T. F. Whale, M. A. Holden, A. N. Kulak, Y. Y. Kim, F. C. Meldrum, H. K. Christenson, B. J. Murray, Phys. Chem. Chem. Phys. 2017, 19, 31186.

[5] I. Lignos, R. Maceiczyk, A. J. deMello, Acc. Chem. Res. 2017, 50, 1248. 
[6] H. H. Shi, Y. Xiao, S. Ferguson, X. Huang, N. Wang, H. X. Hao, Lab Chip 2017, 17, 2167; J. Puigmarti-Luis, Chem. Soc. Rev. 2014, 43, 2253; Y. Y. Kim, C. L. Freeman, X. Q. Gong, M. A. Levenstein, Y. W. Wang, A. Kulak, C. Anduix-Canto, P. A. Lee, S. B. Li, L. Chen, H. K. Christenson, F. C. Meldrum, Angew. Chem. Int. Ed. 2017, 56, 11885; X. Q. Gong, Y. W. Wang, J. Ihli, Y. Y. Kim, S. B. Li, R. Walshaw, L. Chen, F. C. Meldrum, Adv. Mater. 2015, 27, 7395.

[7] L. Li, R. F. Ismagilov, in Annual Review of Biophysics, Vol. 39 (Eds: D. C. Rees, K. A. Dill, J. R. Williamson), 2010, 139; J. M. Schieferstein, A. S. Pawate, M. J. Varel, S. Guha, I. Astrauskaite, R. B. Gennis, P. J. A. Kenis, Lab Chip 2018, 18, 944; C. J. J. Gerard, G. Ferry, L. M. Vuillard, J. A. Boutin, N. Ferte, R. Grossier, N. Candoni, S. Veesler, Cryst. Growth Des. 2018, 18, 5130.

[8] J. Ma, S. M.-Y. Lee, C. Yi, C.-W. Li, Lab Chip 2017, 17, 209; J. M. Wang, Y. J. Song, Small 2017, 13, 19.

[9] B. Spiegel, A. Kafer, M. Kind, Cryst. Growth Des. 2018, 18, 3307; P. Laval, J.-B.

Salmon, M. Joanicot, J. Cryst. Growth 2007, 303, 622; Y. Vitry, S. Teychene, S. Charton, F. Lamadie, B. Biscans, Chem. Eng. Sci. 2015, 133, 54.

[10] M. R. Thorson, S. Goyal, Y. C. Gong, G. G. Z. Zhang, P. J. A. Kenis, CrystEngComm 2012, 14, 2404; V. Bhamidi, S. H. Lee, G. W. He, P. S. Chow, R. B. H. Tan, C. F. Zukoski, P. J. A. Kenis, Cryst. Growth Des. 2015, 15, 3299; A. Yashina, F. Meldrum, A. deMello, Biomicrofluidics 2012, 6, 022001.

[11] G. D. Niu, A. Ruditskiy, M. Vara, Y. N. Xia, Chem. Soc. Rev. 2015, 44, 5806.

[12] F. Schwemmer, C. E. Blanchet, A. Spilotros, D. Kosse, S. Zehnle, H. D. T. Mertens, M. A. Graewert, M. Rossle, N. Paust, D. I. Svergun, F. von Stetten, R. Zengerle, D. Mark, Lab Chip 2016, 16, 1161; K. N. Toft, B. Vestergaard, S. S. Nielsen, D. Snakenborg, M. G. Jeppesen, J. K. Jacobsen, L. Arleth, J. P. Kutter, Anal. Chem. 2008, 80, 3648; J. Kehres, T. 
Pedersen, F. Masini, J. W. Andreasen, M. M. Nielsen, A. Diaz, J. H. Nielsen, O. Hansen, I. Chorkendorff, J. Synchrotron Radiat. 2016, 23, 455.

[13] B. F. B. Silva, M. Zepeda-Rosales, N. Venkateswaran, B. J. Fletcher, L. G. Carter, T. Matsui, T. M. Weiss, J. Han, Y. L. Li, U. Olsson, C. R. Safinya, Langmuir 2015, 31, 4361; R. Dootz, H. Evans, S. Köster, T. Pfohl, Small 2007, 3, 96.

[14] D. S. Khvostichenko, E. Kondrashkina, S. L. Perry, A. S. Pawate, K. Brister, P. J. A. Kenis, Analyst 2013, 138, 5384; A. S. Poulos, M. Nania, P. Lapham, R. M. Miller, A. J. Smith, H. Tantawy, J. Caragay, J. Gummel, O. Ces, E. S. J. Robles, J. T. Cabral, Langmuir 2016, $32,5852$.

[15] A. Ghazal, J. P. Lafleur, K. Mortensen, J. P. Kutter, L. Arleth, G. V. Jensen, Lab Chip 2016, 16, 4263.

[16] M. Moller, S. S. Nielsen, S. Ramachandran, Y. X. Li, G. Tria, W. Streicher, M. V. Petoukhov, R. A. Cerione, R. E. Gillilan, B. Vestergaard, PLoS One 2013, 8, 13.

[17] T. Beuvier, E. A. C. Panduro, P. Kwasniewski, S. Marre, C. Lecoutre, Y. Garrabos, C. Aymonier, B. Calvignac, A. Gibaud, Lab Chip 2015, 15, 2002.

[18] R. Stehle, G. Goerigk, D. Wallacher, M. Ballauff, S. Seiffert, Lab Chip 2013, 13, 1529.

[19] O. Saldanha, R. Graceffa, C. Y. J. Hemonnot, C. Ranke, G. Brehm, M. Liebi, B. Marmiroli, B. Weinhausen, M. Burghammer, S. Köster, ChemPhysChem 2017, 18, 1220. [20] N. Pham, D. Radajewski, A. Round, M. Brennich, P. Pernot, B. Biscans, F. Bonnete, S. Teychene, Anal. Chem. 2017, 89, 2282.

[21] E. Saridakis, N. E. Chayen, Trends Biotechnol. 2009, 27, 99.

[22] B. J. Murray, D. O'Sullivan, J. D. Atkinson, M. E. Webb, Chem. Soc. Rev. 2012, 41, 6519. 


\section{WILEY-VCH}

[23] L. Govada, H. S. Leese, E. Saridakis, S. Kassen, B. Chain, S. Khurshid, R. Menzel, S. Hu, M. S. P. Shaffer, N. E. Chayen, Sci. Rep. 2016, 6, 20053.

[24] C. Marcolli, B. Nagare, A. Welti, U. Lohmann, Atmos. Chem. Phys. 2016, 16, 8915.

[25] S. Köster, T. Pfohl, Mod. Phys. Lett. B 2012, 26, 1230018.

[26] J. A. Newman, P. D. Schmitt, S. J. Toth, F. Y. Deng, S. J. Zhang, G. J. Simpson, Anal. Chem. 2015, 87, 10950.

[27] C. Holtze, A. C. Rowat, J. J. Agresti, J. B. Hutchison, F. E. Angile, C. H. J. Schmitz, S. Köster, H. Duan, K. J. Humphry, R. A. Scanga, J. S. Johnson, D. Pisignano, D. A. Weitz, Lab Chip 2008, 8, 1632.

[28] J. R. Jones, Acta Biomater. 2013, 9, 4457.

[29] Z. A. Kanji, L. A. Ladino, H. Wex, Y. Boose, M. Burkert-Kohn, D. J. Cziczo, M. Krämer, Meteorol. Monogr. 2017, 58, 1.1.

[30] P. Sepulveda, J. R. Jones, L. L. Hench, J. Biomed. Mater. Res. 2001, 58, 734.

[31] S. L. Broadley, B. J. Murray, R. J. Herbert, J. D. Atkinson, S. Dobbie, T. L. Malkin, E. Condliffe, L. Neve, Atmos. Chem. Phys. 2012, 12, 287.

[32] F. C. Meldrum, H. Cölfen, Chem. Rev. 2008, 108, 4332.

[33] N. Sommerdijk, G. de With, Chem. Rev. 2008, 108, 4499; J. Aizenberg, A. J. Black, G. H. Whitesides, J. Am. Chem. Soc. 1999, 121, 4500; J. Ihli, J. N. Clark, A. S. Cote, Y. Y. Kim, A. S. Schenk, A. N. Kulak, T. P. Comyn, O. Chammas, R. J. Harder, D. M. Duffy, I. K. Robinson, F. C. Meldrum, Nat. Commun. 2016, 7, 11878; B. Pokroy, J. Aizenberg, CrystEngComm 2007, 9, 1219.

[34] L. M. Hamm, A. J. Giuffre, N. Han, J. H. Tao, D. B. Wang, J. J. De Yoreo, P. M. Dove, Proc. Natl. Acad. Sci. U. S. A. 2014, 111, 1304.

[35] R. T. Kugler, K. Beissert, M. Kind, Chem. Eng. Res. Des. 2016, 114, 30.

[36] C. N. Nanev, E. Saridakis, N. E. Chayen, Sci. Rep. 2017, 7, 35821. 


\section{WILEY-VCH}

[37] A. L. B. Macon, T. B. Kim, E. M. Valliant, K. Goetschius, R. K. Brow, D. E. Day, A. Hoppe, A. R. Boccaccini, I. Y. Kim, C. Ohtsuki, T. Kokubo, A. Osaka, M. Vallet-Regi, D. Arcos, L. Fraile, A. J. Salinas, A. V. Teixeira, Y. Vueva, R. M. Almeida, M. Miola, C. Vitale-Brovarone, E. Verne, W. Holand, J. R. Jones, J. Mater. Sci. - Mater. Med. 2015, 26, 115.

[38] M. R. Filgueiras, G. Latorre, L. L. Hench, J. Biomed. Mater. Res. 1993, 27, 445.

[39] L. Rybarikova, J. Had, I. Holubova, Ceram-Silikaty 1995, 39, 34.

[40] J. R. Jones, P. Sepulveda, L. L. Hench, J. Biomed. Mater. Res. 2001, 58, 720; D.

Lukito, J. M. Xue, J. Wang, Mater. Lett. 2005, 59, 3267; M. Mackovic, A. Hoppe, R. Detsch, D. Mohn, W. J. Stark, E. Spiecker, A. R. Boccaccini, J. Nanopart. Res. 2012, 14, 966.

[41] D. Kralj, N. Vdovic, Water Res. 2000, 34, 179.

[42] M. G. Lioliou, C. A. Paraskeva, P. G. Koutsoukos, A. C. Payatakes, J. Colloid Interface Sci. 2007, 308, 421.

[43] J. D. Atkinson, B. J. Murray, M. T. Woodhouse, T. F. Whale, K. J. Baustian, K. S. Carslaw, S. Dobbie, D. O'Sullivan, T. L. Malkin, Nature 2013, 498, 355.

[44] N. Fukuta, B. J. Mason, J. Phys. Chem. Solids 1963, 24, 715.

[45] J. M. Campbell, F. C. Meldrum, H. K. Christenson, J. Phys. Chem. C 2015, 119, 1164; A. Kiselev, F. Bachmann, P. Pedevilla, S. J. Cox, A. Michaelides, D. Gerthsen, T. Leisner, Science 2017, 355, 367; M. A. Holden, T. F. Whale, M. D. Tarn, D. O’Sullivan, R. D. Walshaw, B. J. Murray, F. C. Meldrum, H. K. Christenson, Sci. Adv. 2019, 5, eaav4316. [46] J. M. Campbell, F. C. Meldrum, H. K. Christenson, Proc. Natl. Acad. Sci. U. S. A. 2017, 114,810 .

[47] A. D'Arcy, A. Mac Sweeney, A. Haber, Acta Crystallogr. Sect. D: Biol. Crystallogr. 2003, 59, 1343. 


\section{WILEY-VCH}

[48] P. Conrad, G. E. Ewing, R. L. Karlinsey, V. Sadtchenko, J. Chem. Phys. 2005, 122, 064709.

[49] J. L. Holbrough, J. M. Campbell, F. C. Meldrum, H. K. Christenson, Cryst. Growth. Des. 2012, 12, 750; Y. Diao, T. Harada, A. S. Myerson, T. A. Hatton, B. L. Trout, Nat. Mater. 2011, 10, 867.

[50] S. Le Caer, F. Brunet, C. Chatelain, D. Durand, V. Dauvois, T. Charpentier, J. P. Renault, J. Phys. Chem. C 2012, 116, 4748.

[51] D. D. Archibald, S. B. Qadri, B. P. Gaber, Langmuir 1996, 12, 538. 
Table 1. Physical properties of nucleants.

\begin{tabular}{|c|c|c|c|c|}
\hline Nucleant & $\begin{array}{l}\text { Surface Area } \\
{\left[\mathrm{m}^{2} \mathrm{~g}^{-1}\right]}\end{array}$ & $\begin{array}{l}\text { Total Pore Volume } \\
{\left[\mathrm{cm}^{3} \mathrm{~g}^{-1}\right]}\end{array}$ & $\begin{array}{l}\text { Average Pore } \\
\text { Diameter [nm] }\end{array}$ & Chemical/Mineral Composition \\
\hline $\begin{array}{l}\text { Non-porous } \\
\text { bioactive glass }\end{array}$ & $0.52 \pm 0.10$ & - & - & $\begin{array}{c}46.1 \% \mathrm{SiO}_{2}, 24.4 \% \mathrm{Na}_{2} \mathrm{O}, 26.9 \% \mathrm{CaO} \\
\text { and } 2.6 \% \mathrm{P}_{2} \mathrm{O}_{5}\left[\text { ref. }^{[30]}\right]\end{array}$ \\
\hline $\begin{array}{c}\text { Porous } \\
\text { bioactive glass }\end{array}$ & $92.36 \pm 0.46$ & 0.33 & 10.34 & $\begin{array}{c}60 \% \mathrm{SiO}_{2}, 36 \% \mathrm{CaO} \text { and } 4 \% \mathrm{P}_{2} \mathrm{O}_{5} \\
{\left[\text { ref. }^{[30]}\right]}\end{array}$ \\
\hline $\begin{array}{l}\text { Controlled } \\
\text { Porous Glass }\end{array}$ & $146.79 \pm 0.47$ & 0.23 & 5.51 & $95-97 \% \mathrm{SiO}_{2}$ [manufacturer] \\
\hline NX Illite & $76.92 \pm 0.60$ & 0.23 & 15.65 & $\begin{array}{c}\text { 6.6\% Quartz, 9.8\% Feldspar, } 2.1 \% \\
\text { Calcite (removed), } 60.5 \% \text { Illite, } 13.8 \% \\
\text { Mixed illite-smectite and } 7.2 \% \\
\left.\text { Kaolinite [ref. }{ }^{[31]}\right]\end{array}$ \\
\hline
\end{tabular}




\section{WILEY-VCH}
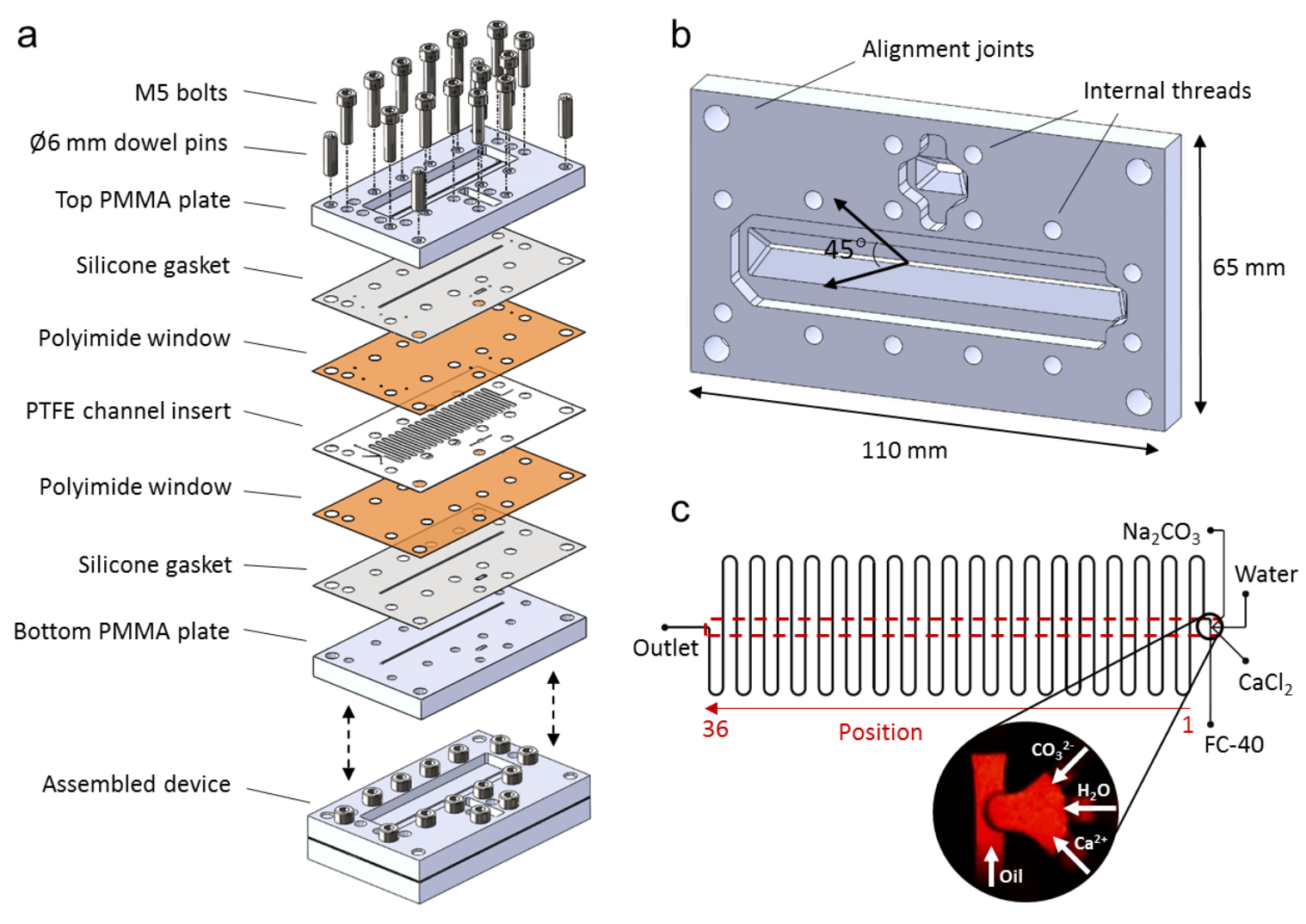

Figure 1. (a) Sketch of the microfluidic device inserts and components along with an assembled device. (b) 3D model of the bottom PMMA plate showing the $45^{\circ}$ expanding cutout and alignment slots for dowel joints. (c) Computer-aided drawing of the channel design showing the $\mathrm{T}$-junction and the 36 viewing positions. The dashed rectangle indicates the region visible through the cutout (not to scale). The inset is a zoomed-in optical micrograph of the T-junction (black circle) showing the one continuous (oil) phase and three reagent inlets. 


\section{WILEY-VCH}

a

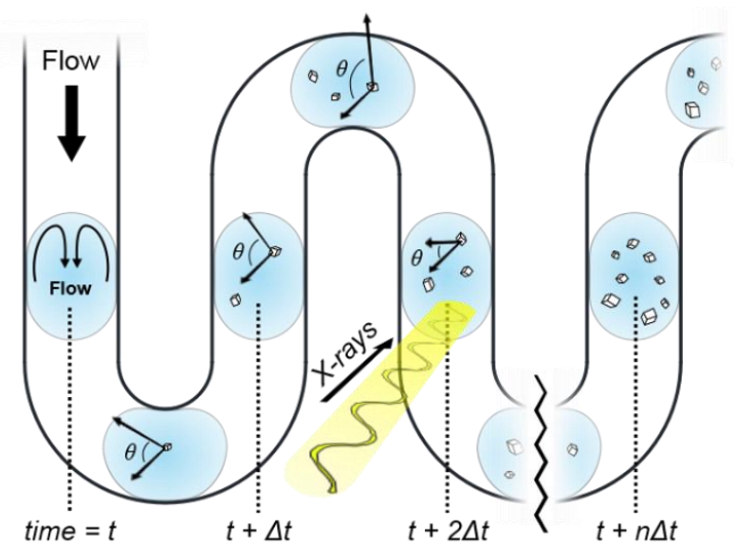

b

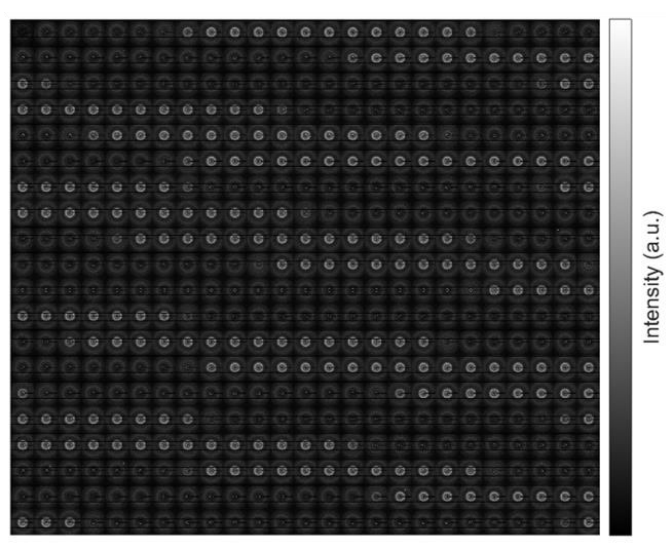

C

Raw 2D Patterns

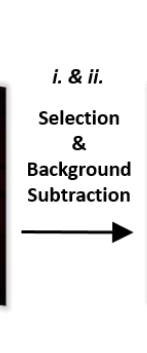

Processed 2D Patterns
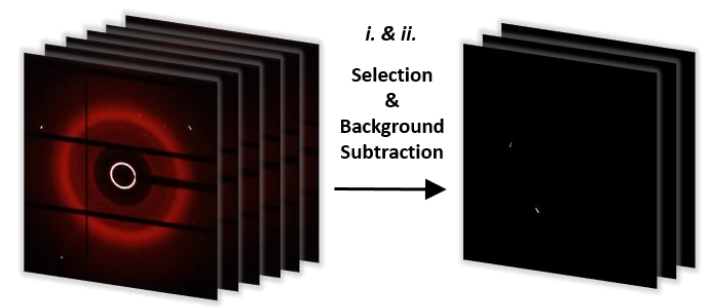

Composite 2D Pattern

Composite 1D Pattern
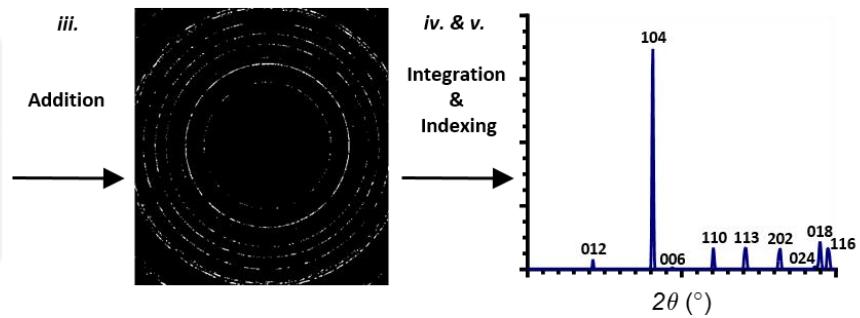

Figure 2. (a) Illustration of the experimental set-up, where an X-ray beam is held at fixed positions on the serpentine channel which correspond to particular time points based on the flow rate and distance traveled. (b) Images of 500 consecutive diffraction patterns of $20 \mathrm{~ms}$ exposure revealing the $\sim 1.5 \mathrm{~Hz}$ flow of water droplets in an experiment with calcite nanoparticles. The brighter and darker frames correspond to the continuous phase and the droplets, respectively. (c) Diagram of the data processing and analysis workflow at a particular location; (i) frames containing oil are discarded; (ii) device and water background are subtracted from selected frames; (iii) processed frames are combined to form a composite 2D diffraction pattern; (iv) the 2D composite pattern is azimuthally integrated to obtain the 'line-profile' 1D diffraction pattern; (v) experimental parameters and reference data are incorporated to enable the identification of specific peaks. 

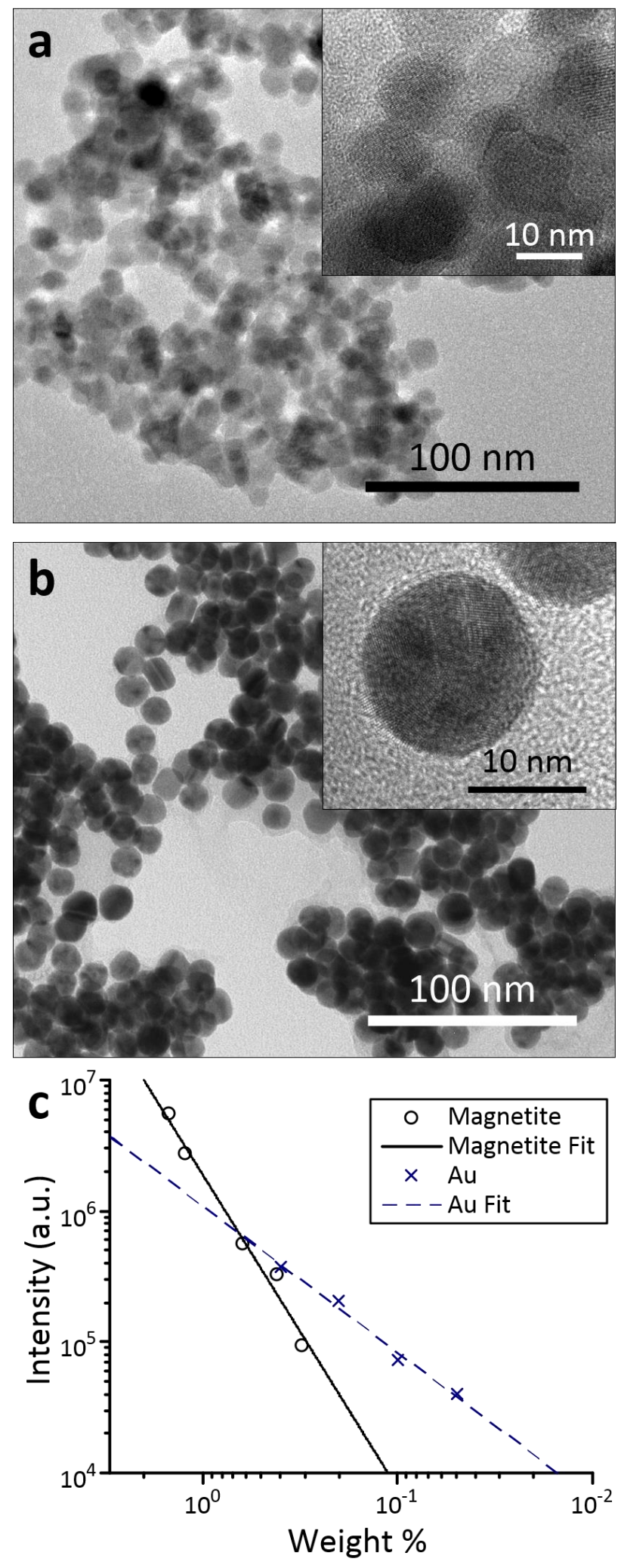

Figure 3. Transmission electron micrographs revealing the size of (a) $11.6 \pm 2.3 \mathrm{~nm}$ magnetite and (b) $15.2 \pm 1.5 \mathrm{~nm}$ gold nanoparticles. (c) Diffraction signal decay of nanoparticles measured by the decrease in the heights of the (311) and (111) reflections of magnetite and gold, respectively, as a function of their concentration within droplets. The decay of both peaks is shown to fit a power law equation, $f(x)=\mathrm{x}^{\mathrm{m}} \cdot 10^{\mathrm{b}}$, where $\mathrm{m}$ is the slope of the $\log -\log$ line and $\mathrm{b}$ is a constant. 


\section{WILEY-VCH}
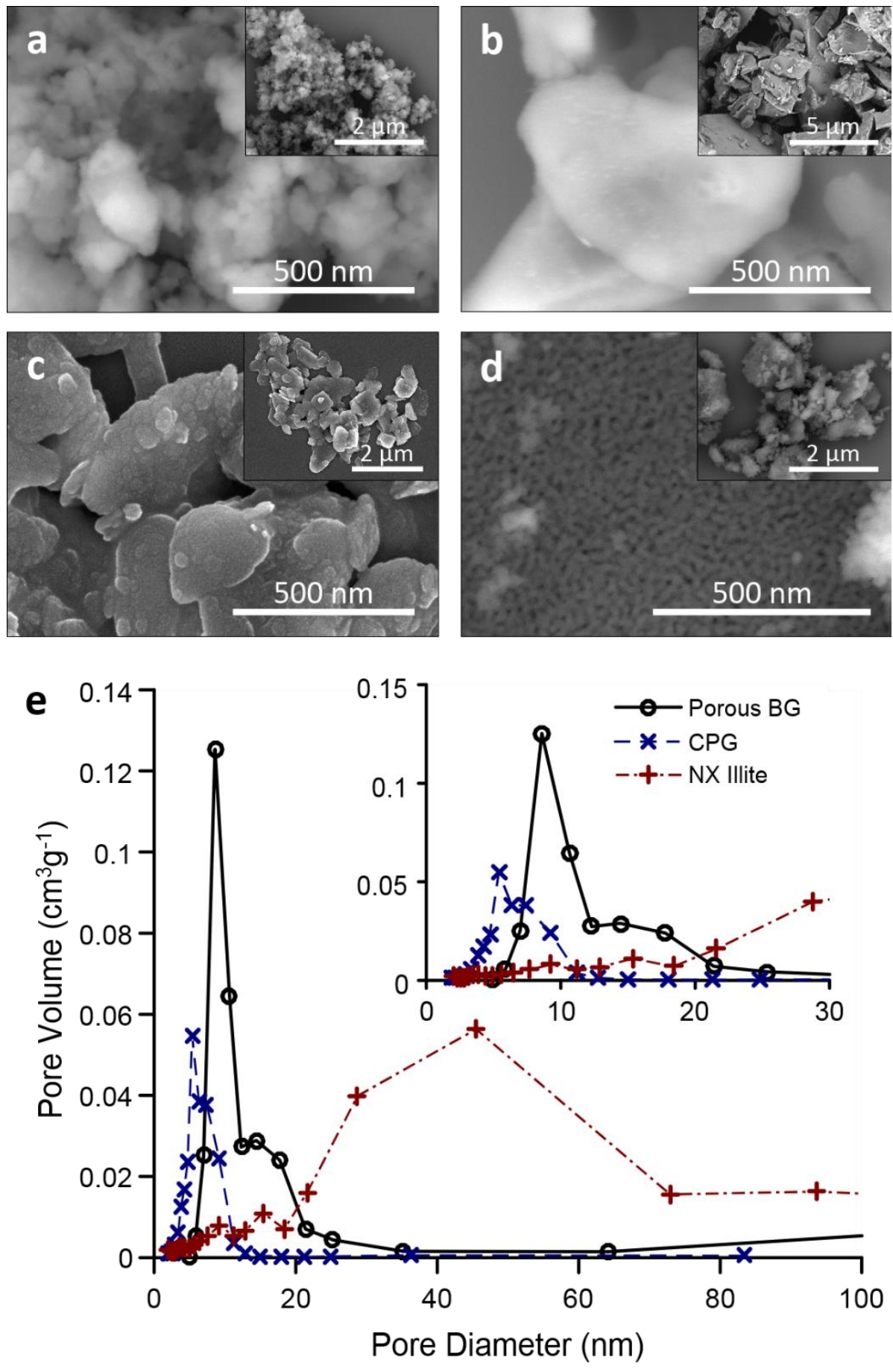

Figure 4. Scanning electron micrographs of (a) porous 58S bioactive glass, (b) non-porous 45S5 bioactive glass, (c) NX Illite and (d) CPG fragments. (e) Pore size distribution of porous bioactive glass, CPG and NX Illite from Barrett-Joyner-Halenda (BJH) $\mathrm{N}_{2}$ desorption measurements. 


\section{WILEY-VCH}
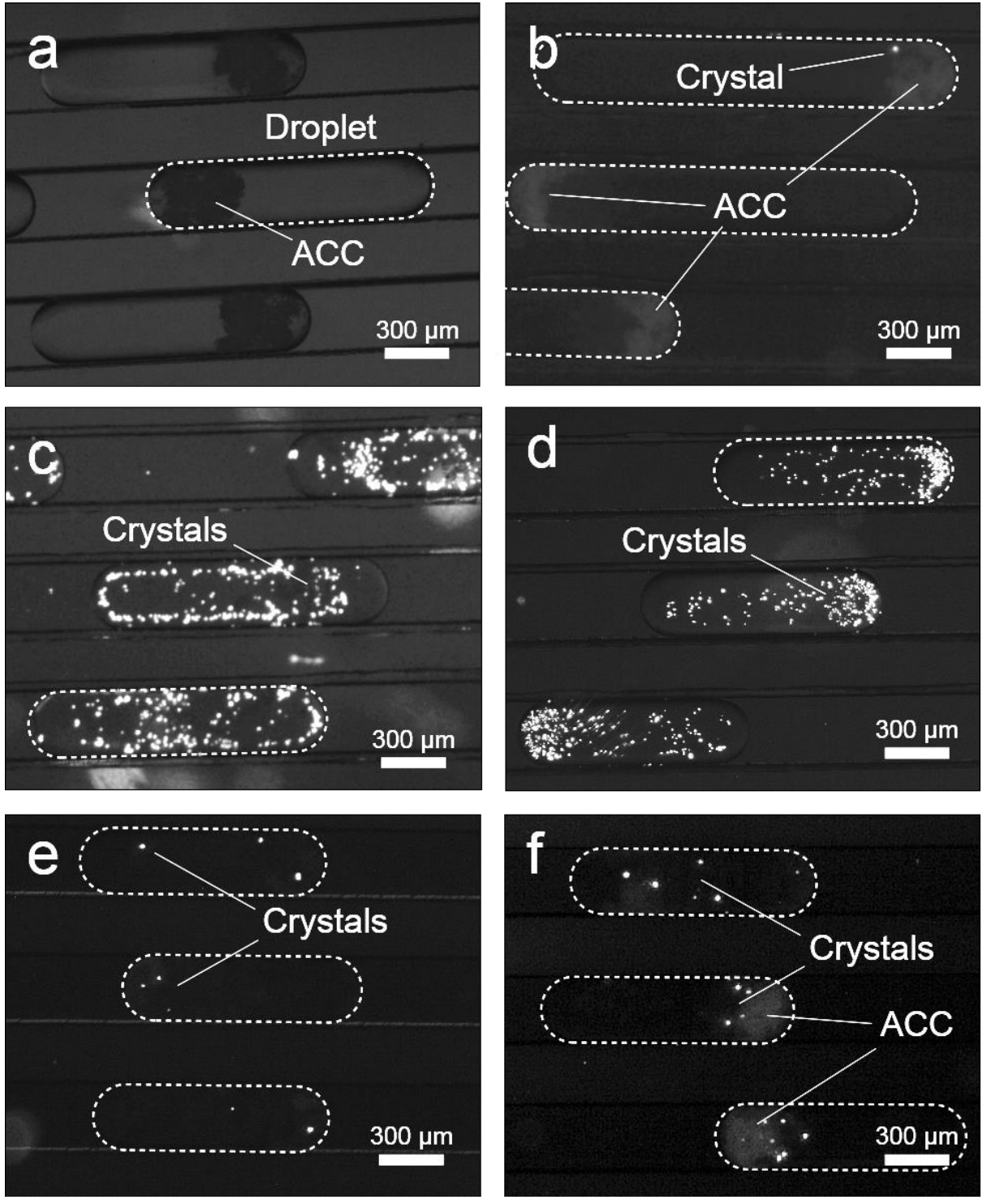

Figure 5. Optical micrographs with near $90^{\circ}$ oriented cross polarizers obtained after flow stoppage in experiments with (a) no nucleants, (b) CPGs, (c) calcite nanoparticles, (d) porous $58 \mathrm{~S}$ bioactive glass, (e) NX illite and (f) non-porous 45S5 bioactive glass. Droplets in all experiments begin filled with metastable ACC, which is depleted due to crystal growth at a rate based on the efficiency of the nucleant. Lower magnification images from each case can be found in Figure S5, Supporting Information. 

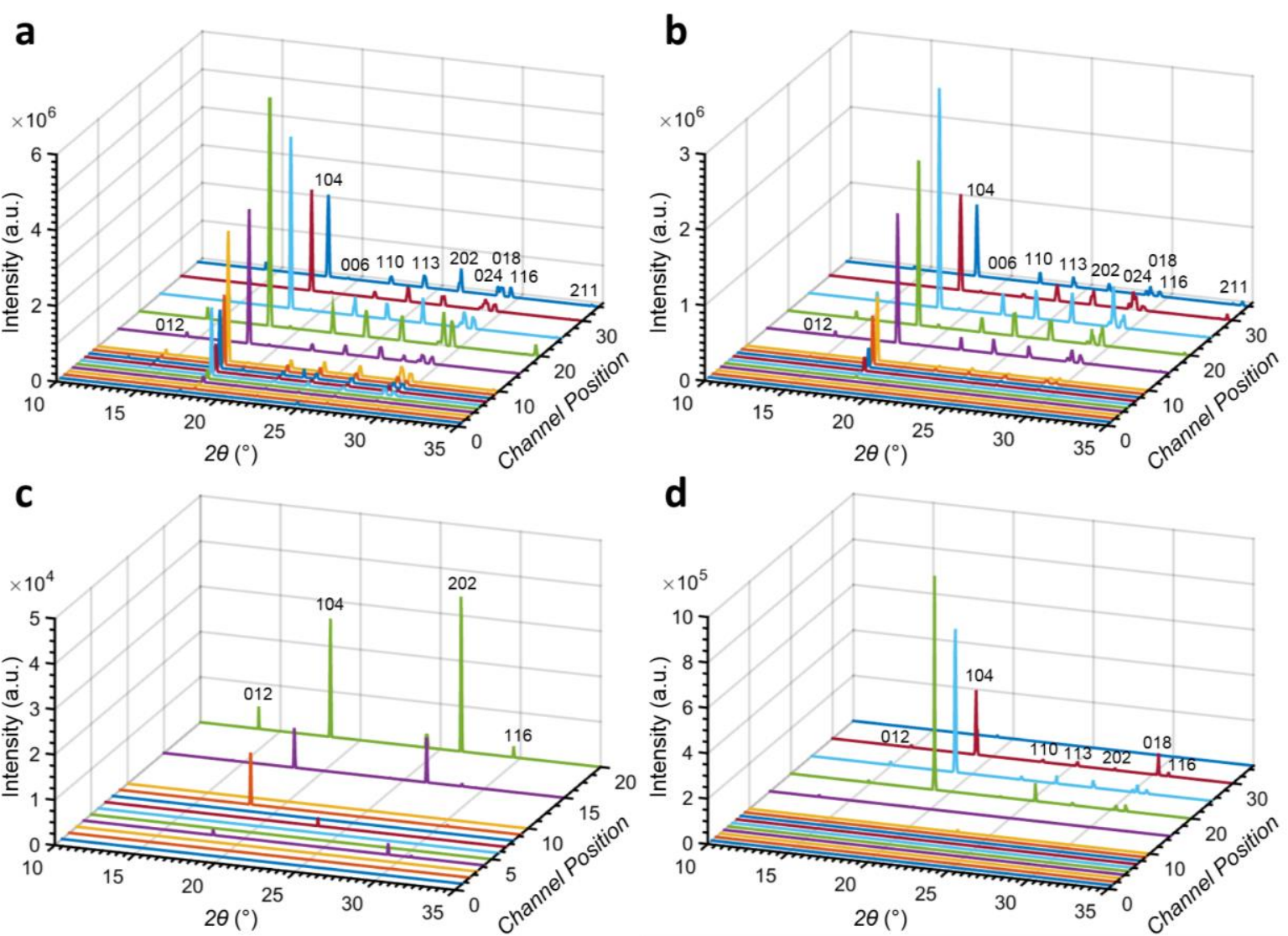

Figure 6. Representative spatially-resolved DMC-XRD measurements for experiments with (a) calcite nanoparticles, (b) porous 58S bioactive glass, (c) NX Illite and (d) non-porous 45S5 bioactive glass. The plots in (a-c) were made by collecting all diffraction obtained from 10 second exposures at the indicated channel positions at ESRF beamline ID13, with the exception of (d) which was made from 20 second exposures at Diamond beamline I22. All labelled peaks correspond to calcite. 


\section{WILEY-VCH}

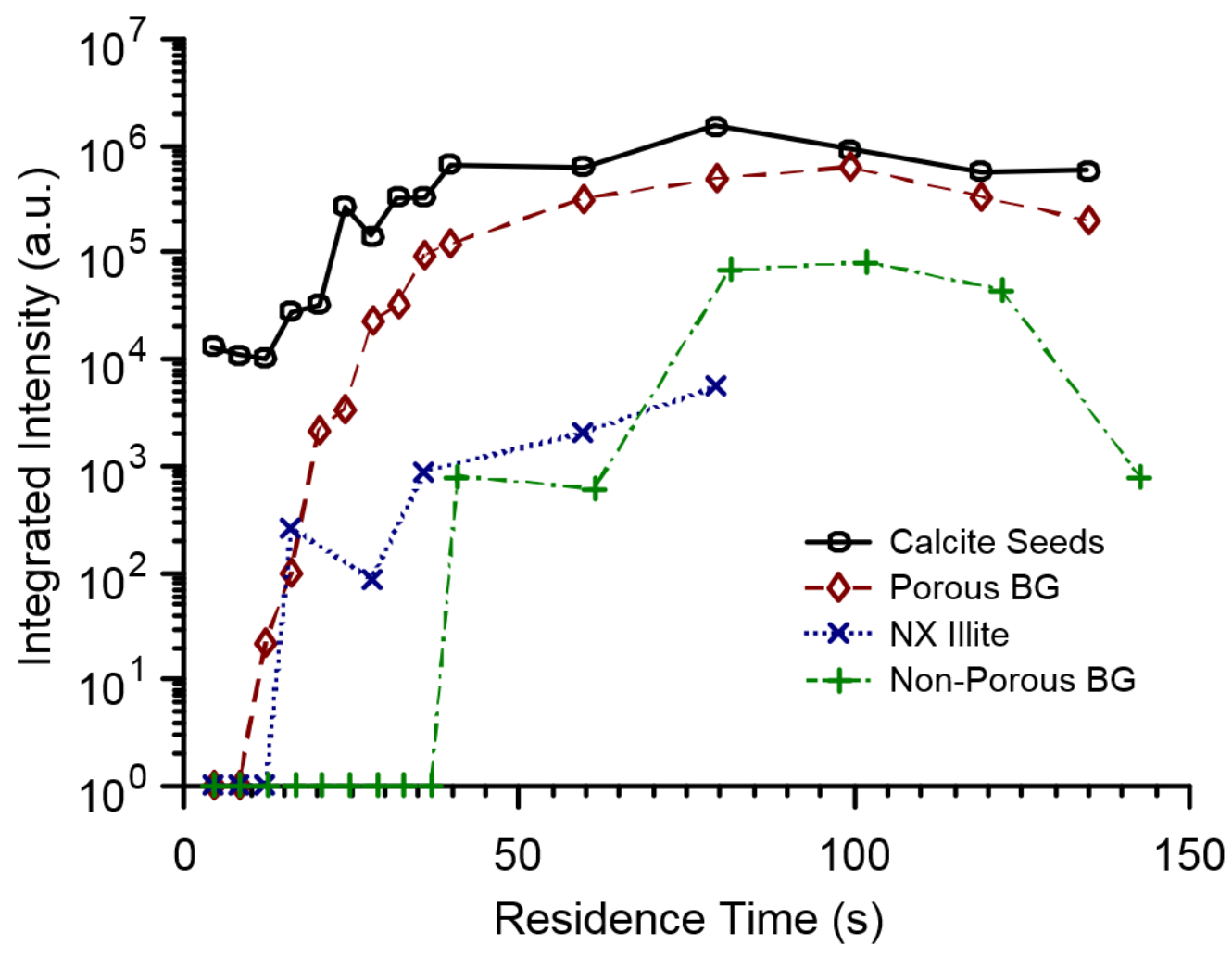

Figure 7. Time-resolved integrated intensity plots comparing diffraction signal growth from experiments with the indicated nucleants. These values were extracted from the area under the diffraction patterns from Figure 6, where the channel position was converted to residence time using the mean droplet velocity, $v_{\text {mean }}$ (see Experimental section). A value of 1 was added to each data point to allow patterns with zero integrated intensity to be plotted on the semi-log graph. 


\section{WILEY-VCH}

Microfluidic sample environments for synchrotron X-ray analysis are emerging as an important new tool for studying materials synthesis. Here, a technique for serial powder diffraction is introduced and used to investigate the nucleation and growth of $\mathrm{CaCO}_{3}$ crystals in the presence of various nucleating agents, where both their surface chemistry and topography are shown to be important to their nucleation efficiency.

\section{Serial Crystallography}

M. A. Levenstein, C. Anduix-Canto, Y.-Y. Kim, M. A. Holden, C. González Niño, D. C. Green, S. E. Foster, A. Kulak, L. Govada, N. E. Chayen, S. J. Day, C. C. Tang, B.

Weinhausen, M. Burghammer, N. Kapur*, and F. C. Meldrum*

\section{Droplet Microfluidics XRD Identifies Effective Nucleating Agents for Calcium}

\section{Carbonate}

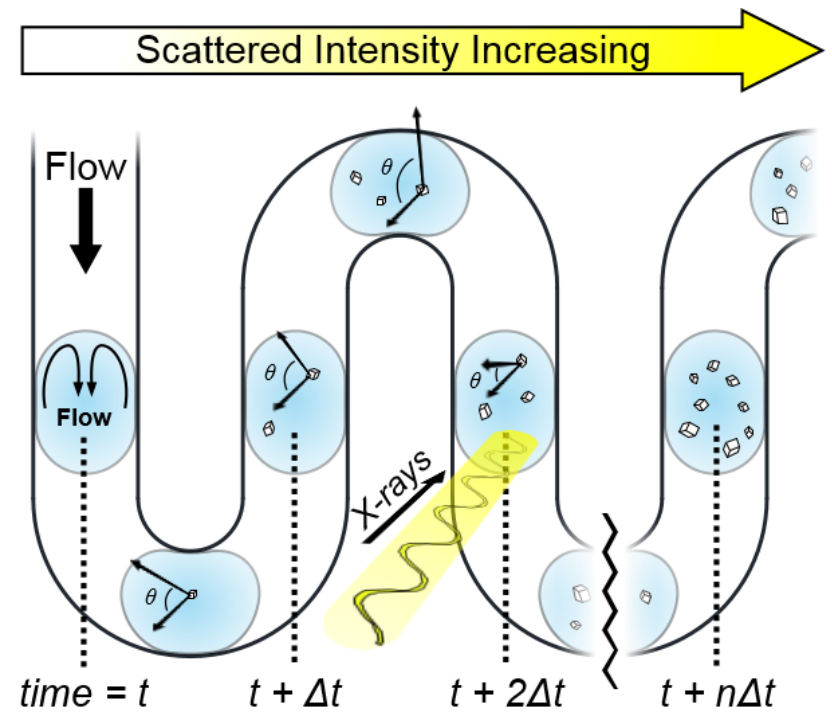


Copyright WILEY-VCH Verlag GmbH \& Co. KGaA, 69469 Weinheim, Germany, 2016.

\section{Supporting Information}

\section{Droplet Microfluidics XRD Identifies Effective Nucleating Agents for Calcium Carbonate}

Mark A. Levenstein, Clara Anduix-Canto, Yi-Yeoun Kim, Mark A. Holden, Carlos González Niño, David C. Green, Stephanie E. Foster, Alexander Kulak, Lata Govada, Naomi E. Chayen, Sarah J. Day, Chiu C. Tang, Britta Weinhausen, Manfred Burghammer, Nikil Kapur*, and Fiona C. Meldrum*

\section{Additional Experimental Methods}

Insert-Based Device Fabrication \& Assembly: Fabrication of microfluidic devices was performed at the EPSRC National Facility for Innovative Robotic Systems housed at the University of Leeds. The top and bottom plates were machined with a DMU 40 eVo 5-axis CNC milling machine (DMG Mori) from $10 \mathrm{~mm}$ thick cast PMMA (Perspex). All device inserts were UV laser-cut from as-received plastic sheets with an LPKF ProtoLaser U3, with the exception of the channels made from PTFE which were laser-cut by Laser Micromachining Ltd (St. Asaph, UK). Gaskets were cut from $300 \mu \mathrm{m}$ thick silicone rubber (TYM Seals \& Gaskets), windows were cut from $75 \mu \mathrm{m}$ thick Kapton (RS) or $50 \mu \mathrm{m}$ thick polyethylenimine (PEI, Goodfellow), and channel inserts were cut from $300 \mu \mathrm{m}$ thick PTFE (Goodfellow) or $250 \mu \mathrm{m}$ thick Kapton (Katco). The devices were assembled in a laminar flow cabinet or low dust environment with the aid of $\emptyset 6 \mathrm{~mm}$ dowel pins. After assembly, devices were secured with M5 bolts and the channels were made hydrophobic using a chemical treatment process with Aquapel as described by Mazutis et al. ${ }^{[1]}$

PDMS Microfluidic Device Fabrication: Microfluidic devices made from polydimethylsiloxane (PDMS) were fabricated using standard soft lithographic methods. ${ }^{[2]}$ The PDMS base and curing agent (Dowsil Sylgard 184) were mixed in a 10:1 ratio, poured 


\section{WILEY-VCH}

into a mold bearing the channel design and degassed in a vacuum desiccator. The molds were then placed in an oven at $60{ }^{\circ} \mathrm{C}$ overnight, and subsequently the cured PDMS was cut out with a razor. Flat PDMS slabs which serve as the device substrate were made using the same method. $1 \mathrm{~mm}$ diameter holes were punched in the PDMS chips and then both the chips and substrates were place in an ultrasonic bath in $0.5 \mathrm{M} \mathrm{NaOH}$ for 5 minutes, rinsed with water and ethanol, respectively, and air dried. The surfaces were activated for bonding by placing the sides to be joined face-up in an air-based plasma cleaner (Harrick Plasma) for $45 \mathrm{~s}$. The surfaces were then brought into contact and placed in an oven at $60{ }^{\circ} \mathrm{C}$ for several hours to form a strong bond. Finally, the devices were made hydrophobic using the same chemical treatment process as with the insert-based device.

Nanoparticle Synthesis \& Characterization: To synthesize the magnetite nanoparticles, 170 $\mathrm{mL}$ of DI water was added to a $500 \mathrm{~mL}$ round-bottom flask and heated under reflux at $90{ }^{\circ} \mathrm{C}$ for an hour to remove dissolved oxygen. $1.668 \mathrm{~g} \mathrm{FeSO} 4 \cdot 7 \mathrm{H}_{2} \mathrm{O}$ and $3.244 \mathrm{~g} \mathrm{FeCl} \cdot 6 \mathrm{H}_{2} \mathrm{O}$ were added under vigorous stirring to yield a deep pearlescent orange solution. When all solids were dissolved, $7.57 \mathrm{~mL}$ of $28 \%$ ammonia was added quickly into the solution, which instantly turned black. This was allowed to stir at $90{ }^{\circ} \mathrm{C}$ for $1 \mathrm{~h}$. Meanwhile, $4.537 \mathrm{~g}$ of citric acid trisodium salt dihydrate was dissolved in $100 \mathrm{~mL}$ DI water. When the iron oxide reaction had been left for $1 \mathrm{~h}$, the citric acid solution was added quickly to yield a final volume of 270 mL containing $0.006 \mathrm{~mol} \mathrm{Fe}{ }^{2+}, 0.012 \mathrm{~mol} \mathrm{Fe}^{3+}$, (approx.) $0.054 \mathrm{~mol} \mathrm{NH} 3 \cdot \mathrm{H}_{2} \mathrm{O}$ and $0.015 \mathrm{~mol}$ citric acid. Here, the most important thing is the molar ratio between di and trivalent iron (1:2). This was stirred and heated at $90{ }^{\circ} \mathrm{C}$ for $1 \mathrm{~h}$ before the heat was removed, and the solution was allowed to cool to room temperature naturally. Superparamagnetic particles were isolated by precipitation. The nanoparticle suspension was added to approx. $300 \mathrm{~mL}$ acetone and allowed to flocculate over $5 \mathrm{~min}$. The flocculant was sedimented using a rare- 


\section{WILEY-VCH}

earth magnet, and the supernatant decanted away. The nanoparticles were then redissolved in about $50 \mathrm{~mL}$ water, and reprecipitated with $200 \mathrm{~mL}$ acetone. This washing procedure was repeated a number of times before the flocculated nanoparticles were collected by filtration and stored as a dry powder.

Gold nanoparticles were synthesized by the Turkevich-Frens method. ${ }^{[3]}$ Briefly, $0.25 \mathrm{mM}$ of tetrachloroauric acid was dissolved in $400 \mathrm{~mL}$ of DI water in a $500 \mathrm{~mL}$ two-necked roundbottomed flask connected to a condenser. After dissolution, the solution was heated until boiling in an oil bath, at which time $20 \mathrm{~mL}$ of $38 \mathrm{mM}$ sodium citrate was added. The color of solution turned transparent, to purple and then to ruby red. The solution was stirred for 20 min before cooling down to room temperature using a bath of cold water, and then concentrated by centrifugation.

Calcite nanoparticles were synthesized using a method adapted from Green et al. ${ }^{[4]}$ Briefly, $0.44 \mathrm{~g}$ of $\mathrm{CaO}$ was added to degassed $\mathrm{DI}$ water under reflux conditions $\left(80^{\circ} \mathrm{C}, \mathrm{N}_{2}\right.$ atmosphere) and stirred for $15 \mathrm{~min}$. The solution was then allowed to age for $16 \mathrm{hr}$ by turning off the heat and stirrer and sealing the container. After this time, the solution was carbonated using a 3:1 $\mathrm{N}_{2}: \mathrm{CO}_{2}$ gas mixture until the $\mathrm{pH}$ reached 8 . The calcite nanoparticles were then isolated by centrifugation and washed twice with ethanol.

The average sizes of the of all nanoparticles was determined by transmission electron microscopy (TEM) using an FEI Tecnai TF20 FEG-TEM after dispersing a powder sample in ethanol and drying it onto a carbon-coated $\mathrm{Cu}$ grid. 


\section{WILEY-VCH}

DMC-XRD Data Processing: A MATLAB algorithm was developed to cycle through the frames of a particular time-resolved exposure, where frames containing oil scattering are discarded and frames containing water scattering are background subtracted. The background subtraction routine consists of subtracting a frame from the same exposure, but one not containing any crystals, from the target frames. It is not possible to use a single background reference for all channels for all experiments as small differences in sample-to-detector distance, texturing/imperfections in the windows, and possible beam clipping of channel walls, make each exposure too unique for application of a universal background reference. Any remaining background noise is removed with a threshold identified for each experiment. These frames are summed together to form a composite 2D pattern incorporating all the diffraction observed during that exposure. This pattern is then integrated, and the detector parameters (pixel size, aspect ratio) and the sample-to-detector distance are taken into account to produce a $1 \mathrm{D}$ pattern displaying intensity as a function of $2 \theta$. Reference data for particular crystal polymorphs are then plotted against these 1D patterns to identify particular peaks, where errors in peak position are typically $<0.05^{\circ}$.

Turbidity Measurements: The turbidity measurements were conducted with a Perkin Elmer Lambda $35 \mathrm{UV}-\mathrm{V}$ is double-beam spectrometer according to the method described by Wang et al. ${ }^{[5]}$ In this study, $0.5 \mathrm{~mL}$ of $100 \mathrm{mM} \mathrm{Na} 2 \mathrm{CO}_{3}$ was loaded into a PMMA cuvette and subsequently mixed with $0.5 \mathrm{~mL}$ of $100 \mathrm{mM} \mathrm{CaCl}_{2}$ prepared with $0.01 \%$ w/w of the selected nucleant. After allowing the solutions $10 \mathrm{sec}$ to mix, the transmission of $500 \mathrm{~nm}$ wavelength light through the cuvette was monitored every second for 10 minutes. All experiments were performed at least three times for each nucleant. 


\section{WILEY-VCH}

Characterization of Crystals Collected From Droplets: Droplets were collected from the device outlet into a $1.5 \mathrm{~mL}$ centrifuge tube (Eppendorf) and transferred into a $1 \mathrm{~mL}$ syringe (NORM-JECT). This solution was filtered using a $0.2 \mu \mathrm{m}$ polycarbonate membrane (Sterlitech) in a $13 \mathrm{~mm}$ stainless steel Swinny syringe filter holder, and subsequently washed with $5 \mathrm{~mL}$ of hexane and $5 \mathrm{~mL}$ of ethanol in order to remove the oil and stop the reaction, respectively. The membranes were then dried in an oven at $60{ }^{\circ} \mathrm{C}$, mounted on aluminum stubs with copper tape and imaged with SEM as above.

\section{Supporting References}

[1] L. Mazutis, J. Gilbert, W. L. Ung, D. A. Weitz, A. D. Griffiths, J. A. Heyman, Nat. Protoc. 2013, 8, 870.

[2] J. C. McDonald, G. M. Whitesides, Acc. Chem. Res. 2002, 35, 491.

[3] J. Huhn, C. Carrillo-Carrion, M. G. Soliman, C. Pfeiffer, D. Valdeperez, A. Masood, I. Chakraborty, L. Zhu, M. Gallego, Z. Yue, M. Carril, N. Feliu, A. Escudero, A. M. Alkilany, B. Pelaz, P. del Pino, W. J. Parak, Chem. Mater. 2017, 29, 399.

[4] D. C. Green, J. Ihli, P. D. Thornton, M. A. Holden, B. Marzec, Y. Y. Kim, A. N. Kulak, M. A. Levenstein, C. Tang, C. Lynch, S. E. D. Webb, C. J. Tynan, F. C. Meldrum, Nat. Commun. 2016, 7, 13.

[5] Y. W. Wang, Y. Y. Kim, C. J. Stephens, F. C. Meldrum, H. K. Christenson, Cryst. Growth Des. 2012, 12, 1212. 


\section{WILEY-VCH}

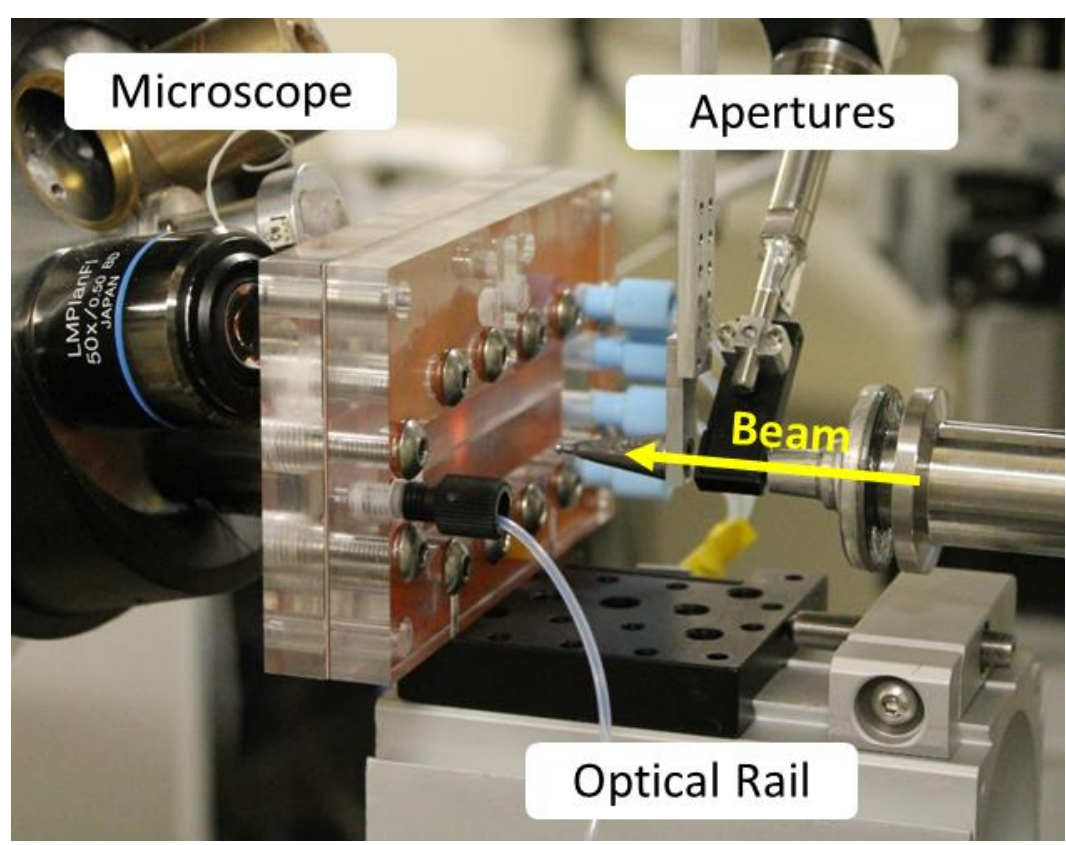

Figure S1: An insert-based microfluidic device mounted on an optical rail carriage at ESRF beamline ID13, while the inline positioning microscope was in place. 


\section{WILEY-VCH}
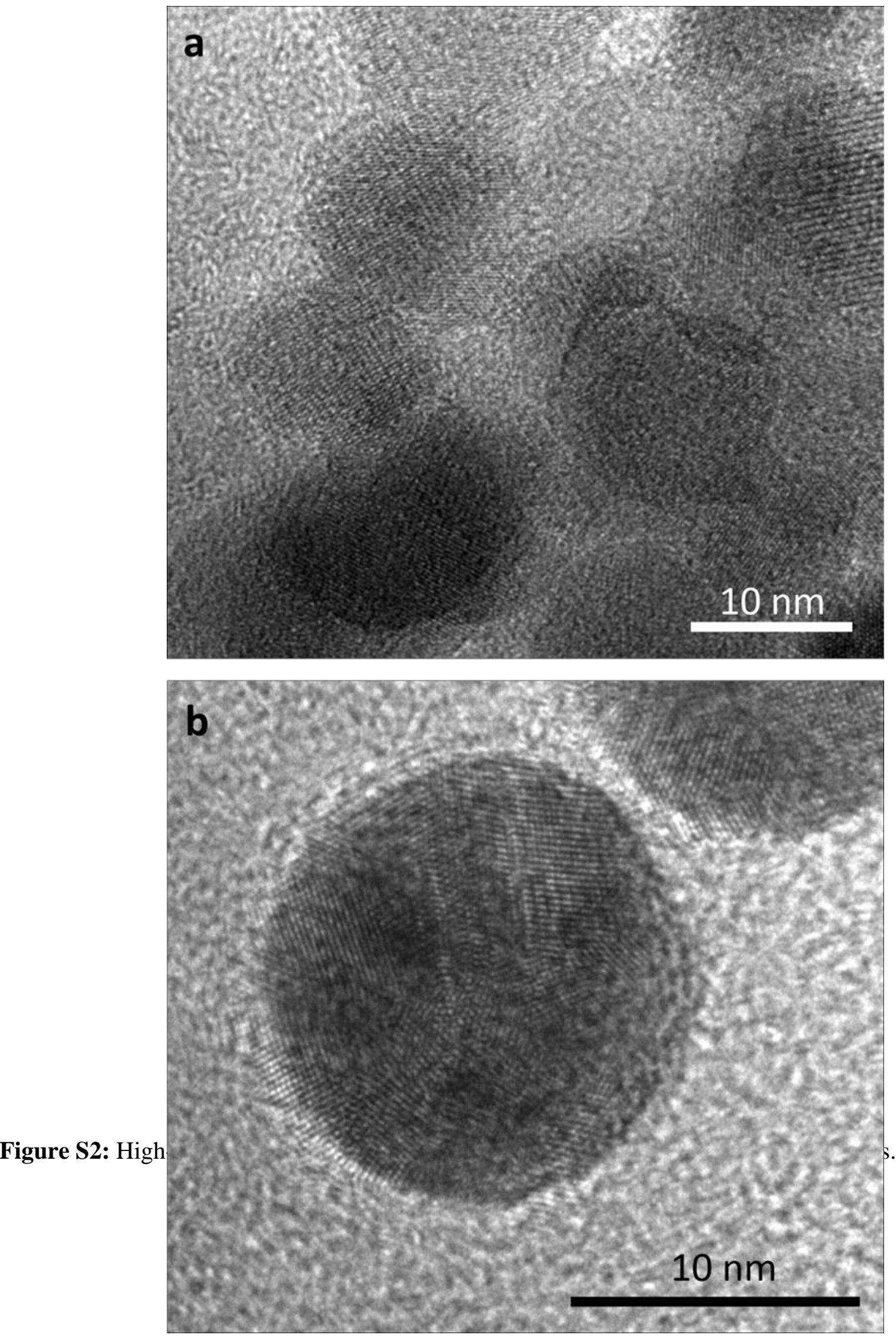
WILEY-VCH
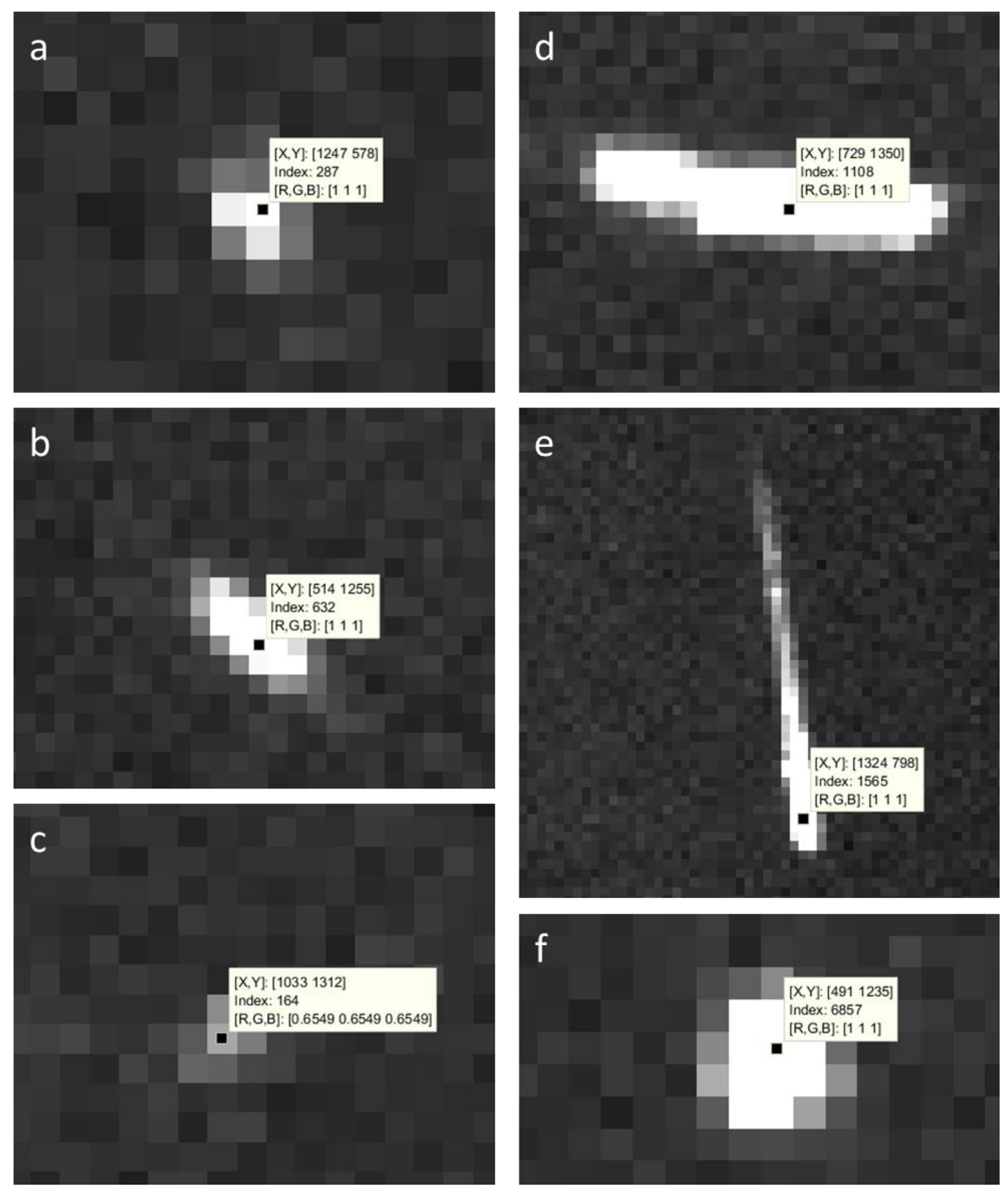

Figure S3: Representative single calcite (104) reflections from raw single $20 \mathrm{~ms}$ exposures taken at ESRF beamline ID13. The images contained in (a-c) are from Position 2 and the images contained in (d-f) are from Position 20 during a calcite nanoparticle-seeded experiment. The $[\mathrm{X}, \mathrm{Y}]$ values are the pixel coordinates, and the Index value is the intensity in arbitrary units. The RGB values refer to the greyscale shade of the pixel based on the 0-250 scaling of the rendered imaged, i.e. pixels with an intensity of 0 appear black, pixels between 0 and 250 are various shades of grey and pixels $\geq 250$ appear white. 


\section{WILEY-VCH}
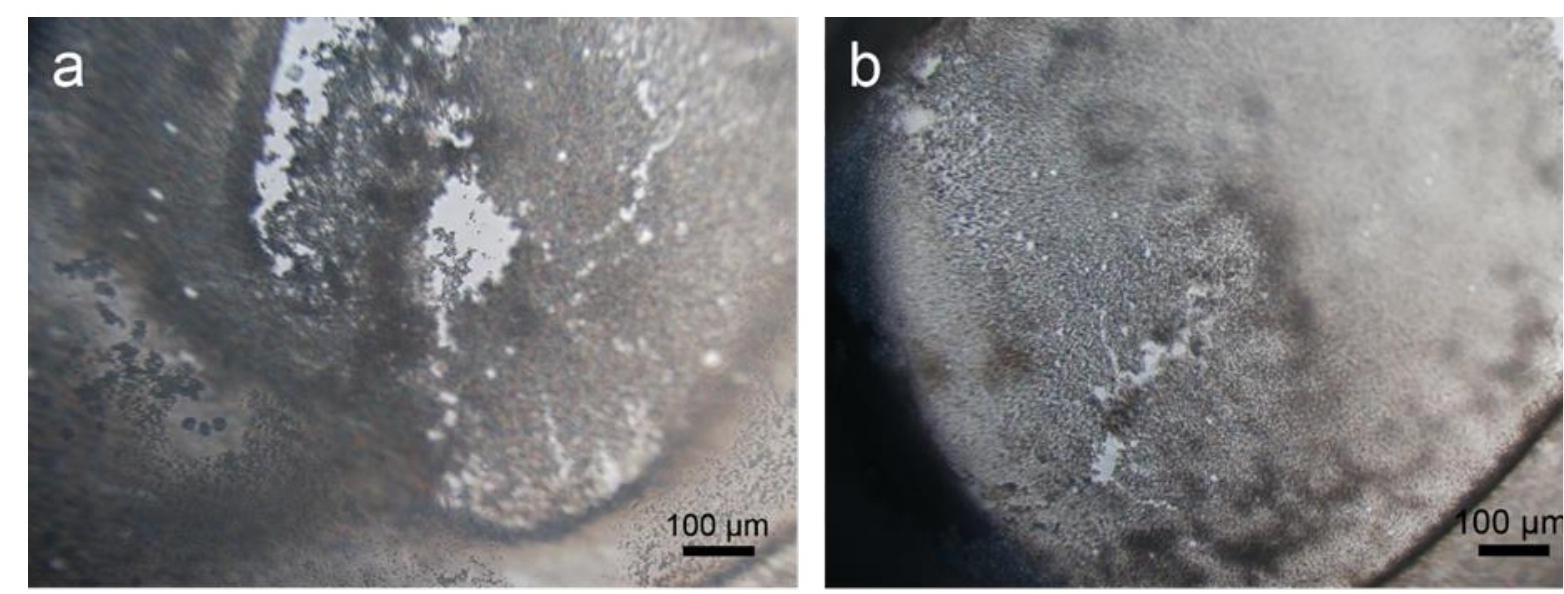

Figure S4: Optic
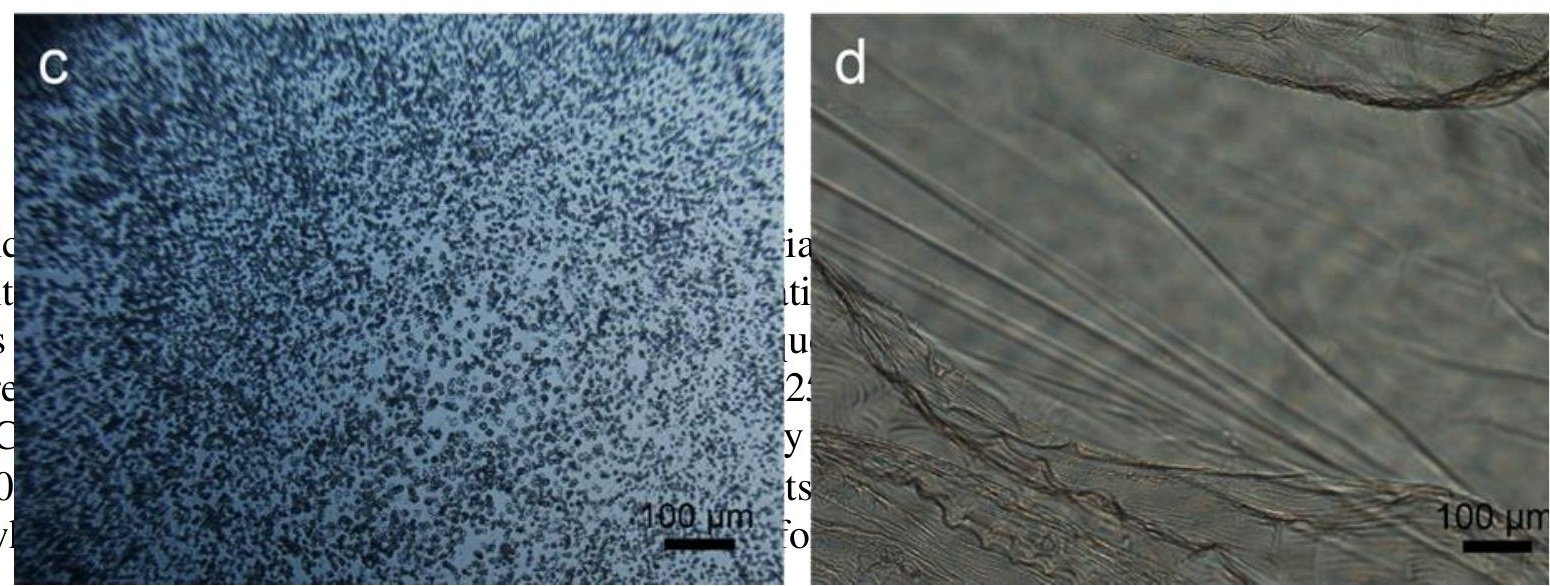


\section{WILEY-VCH}
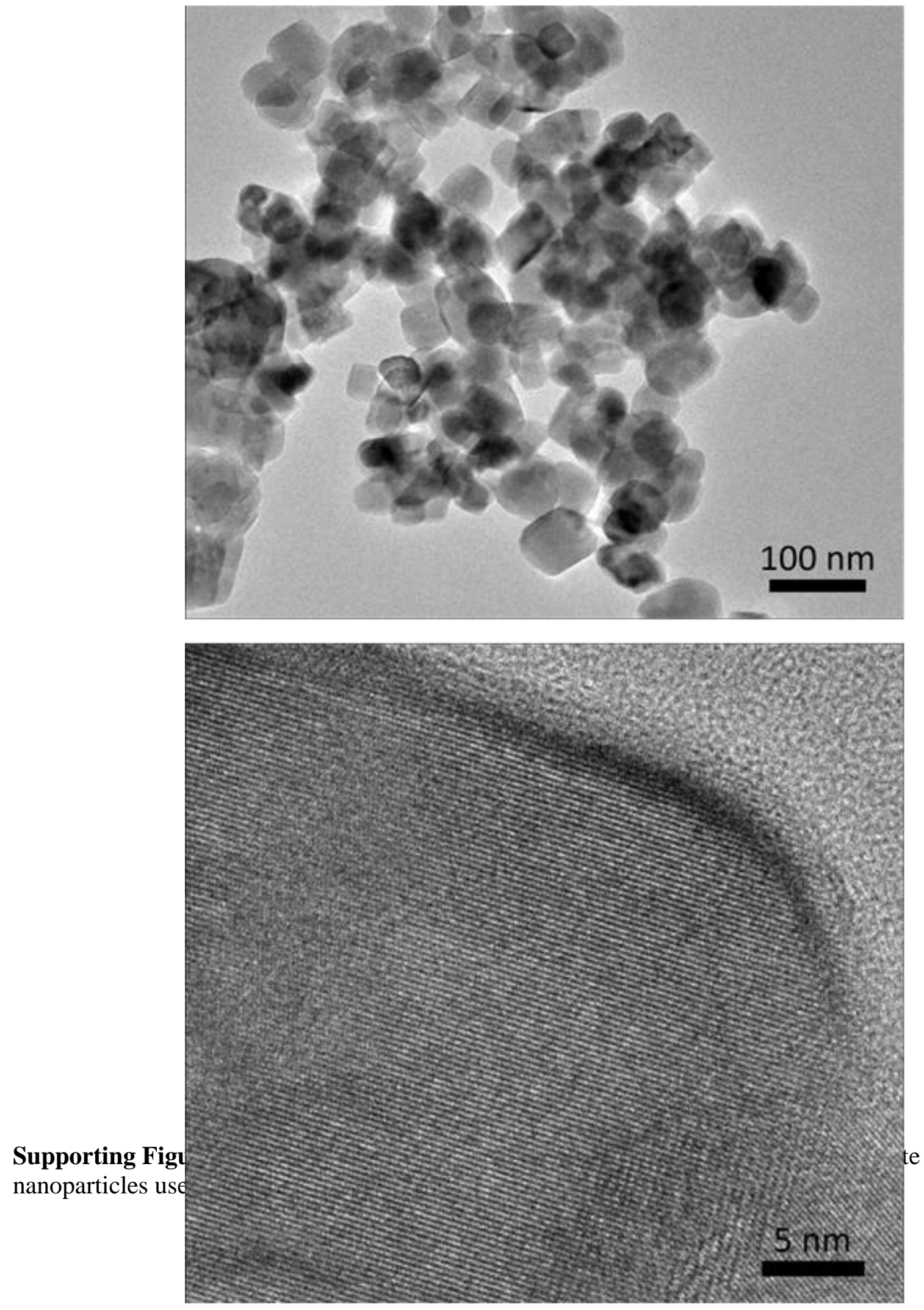


\section{WILEY-VCH}

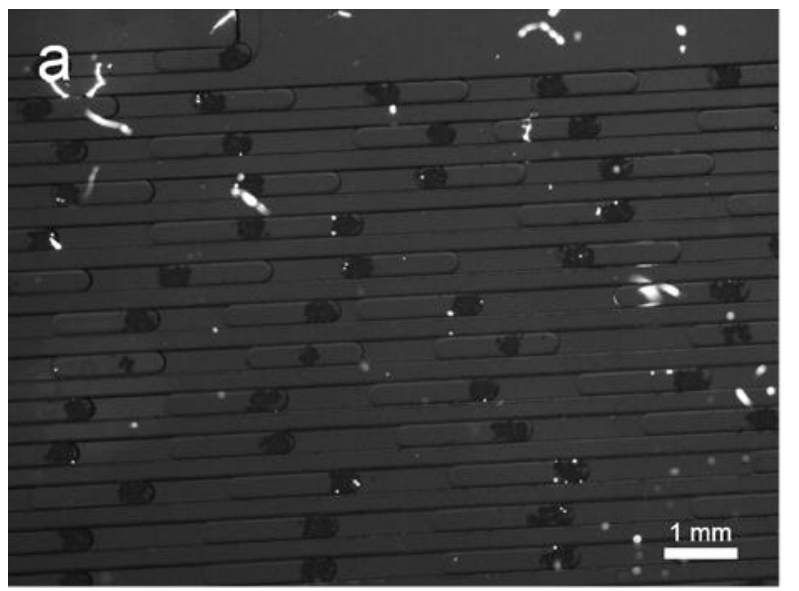

b
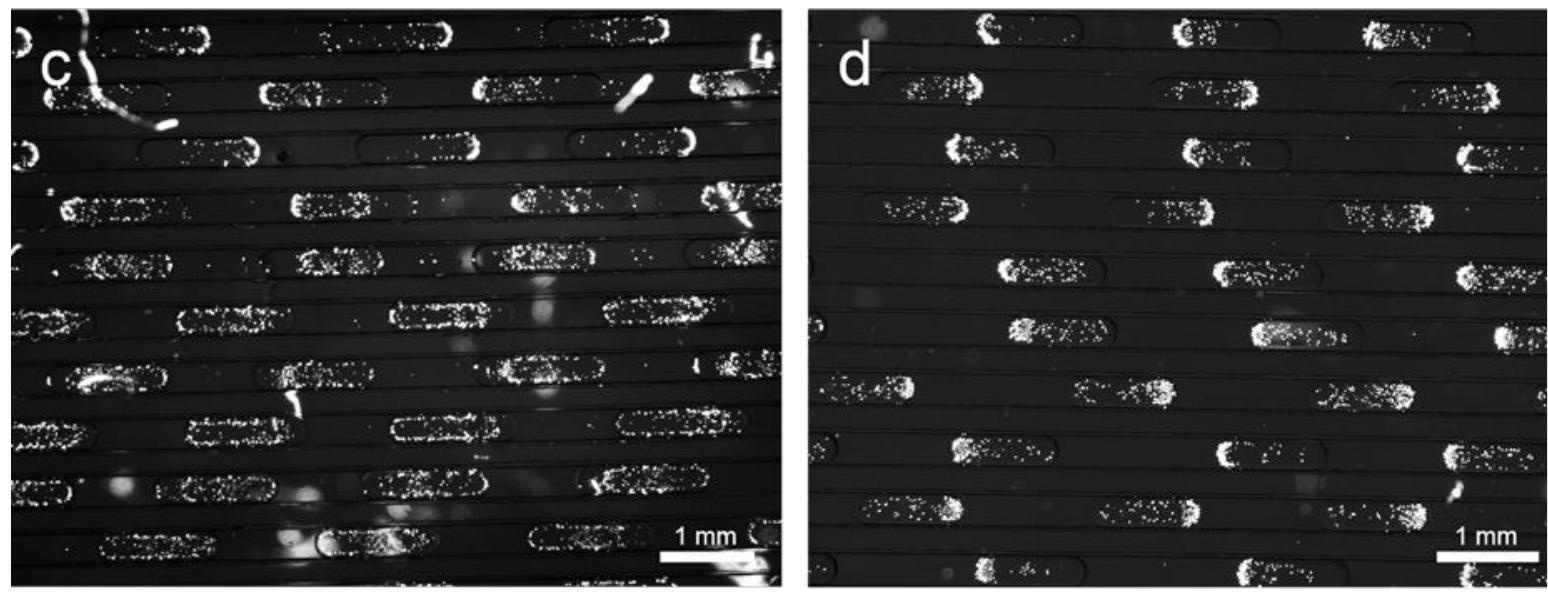

Figure S6: Low

(a) without nucle $\mathbf{e}$ after $1 \mathrm{~min}$, (d) $\mathrm{p}$ porous $45 \mathrm{~S} 5$ bio
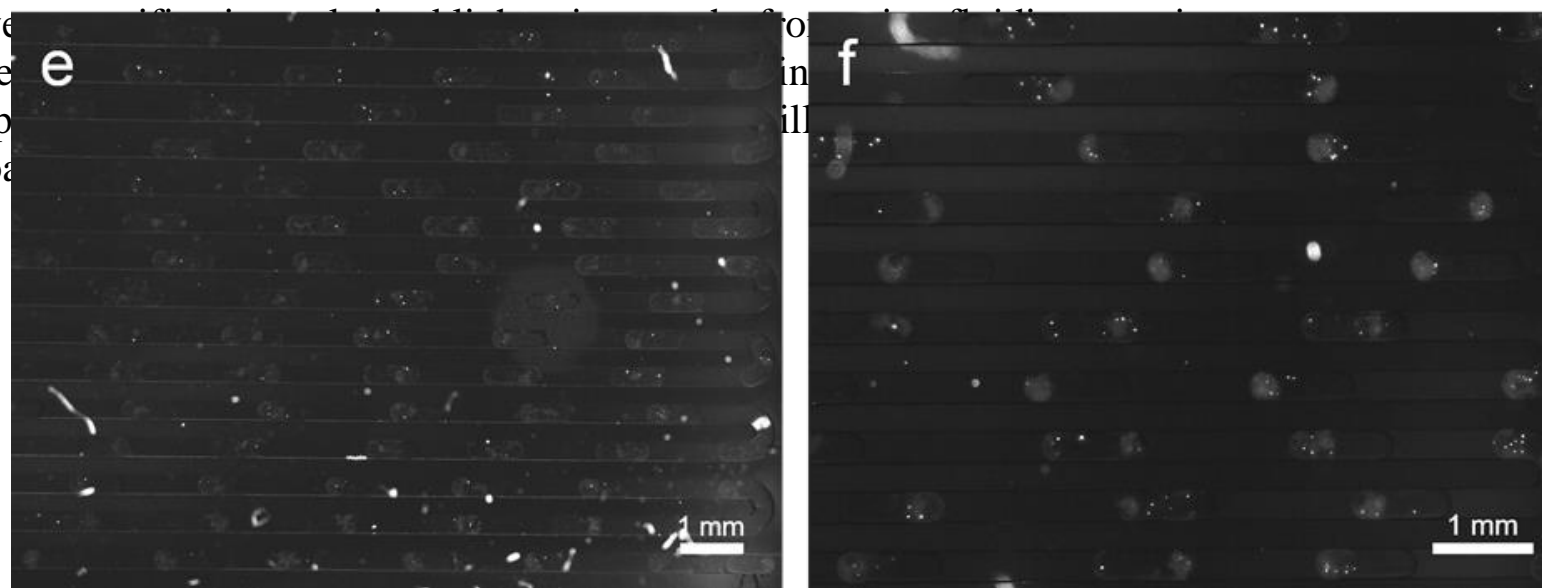

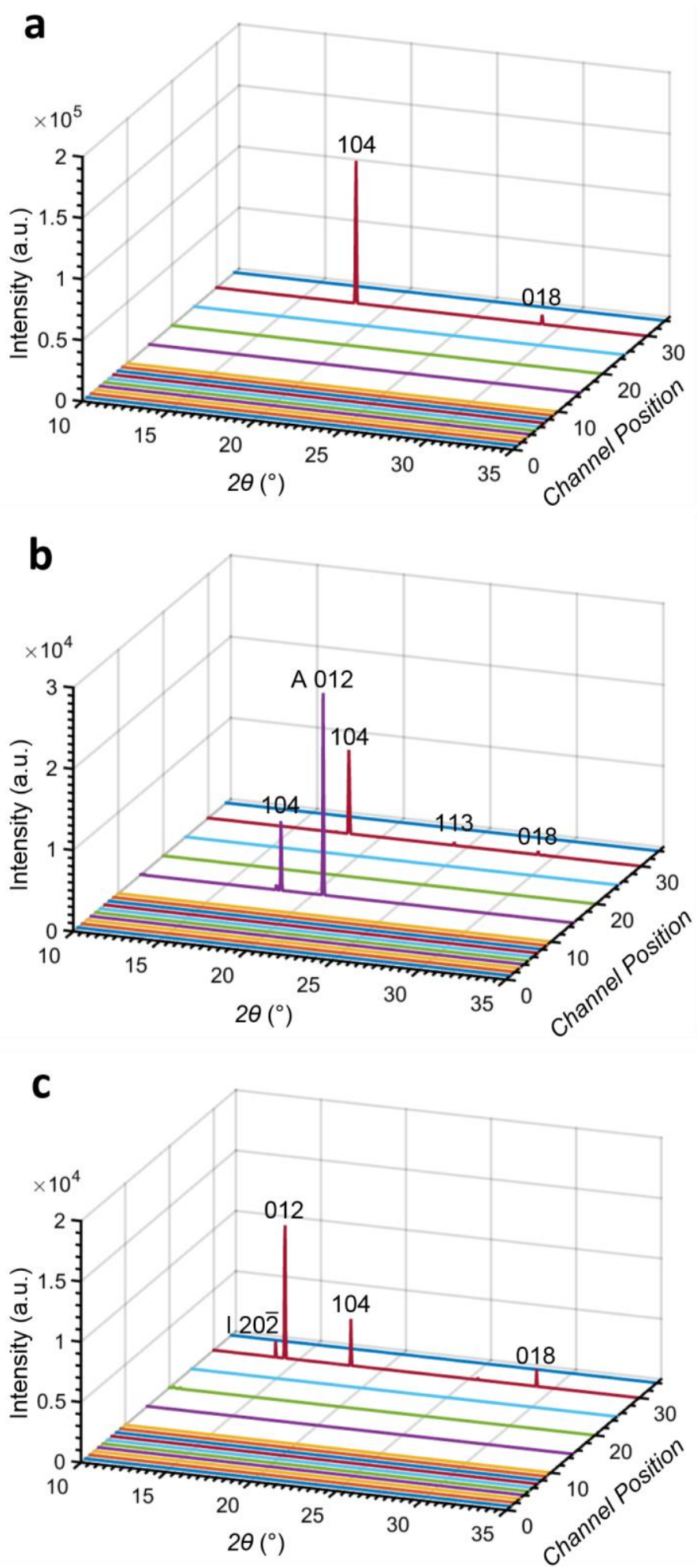

Figure S7: Representative spatially-resolved DMC-XRD measurements for experiments with (a) CPGs, (b) carboxylate-functionalized CPGs and (c) no nucleants. All peaks correspond to calcite and are labelled with their respective lattice plane except for the peaks marked A 012 and I $20 \overline{2}$ which match most closely to peaks from aragonite and ikaite $\left(\mathrm{CaCO}_{3} \cdot 6 \mathrm{H}_{2} \mathrm{O}\right)$, respectively. It is important to note that in runs with low nucleation rates, observed diffraction likely comes from device scale, and the low number and intensity of reflections and low signal-to-noise ratio makes processing and indexing more difficult. 
WILEY-VCH

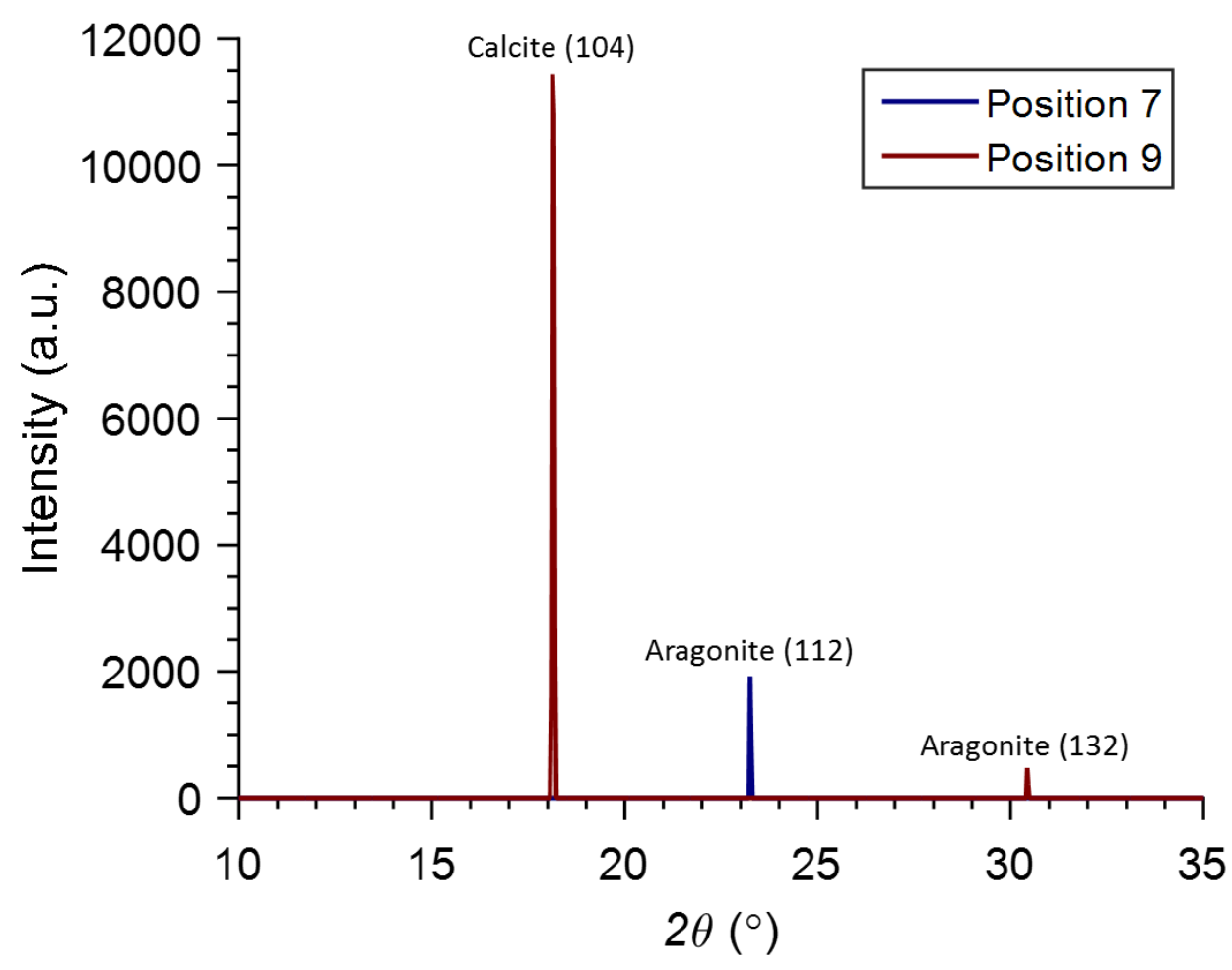

Figure S8: Diffraction patterns from Position 7 (blue) and Position 9 (red) from an NX illite experiment. These patterns contain some peaks which correspond only to aragonite and not calcite or vaterite. 
WILEY-VCH
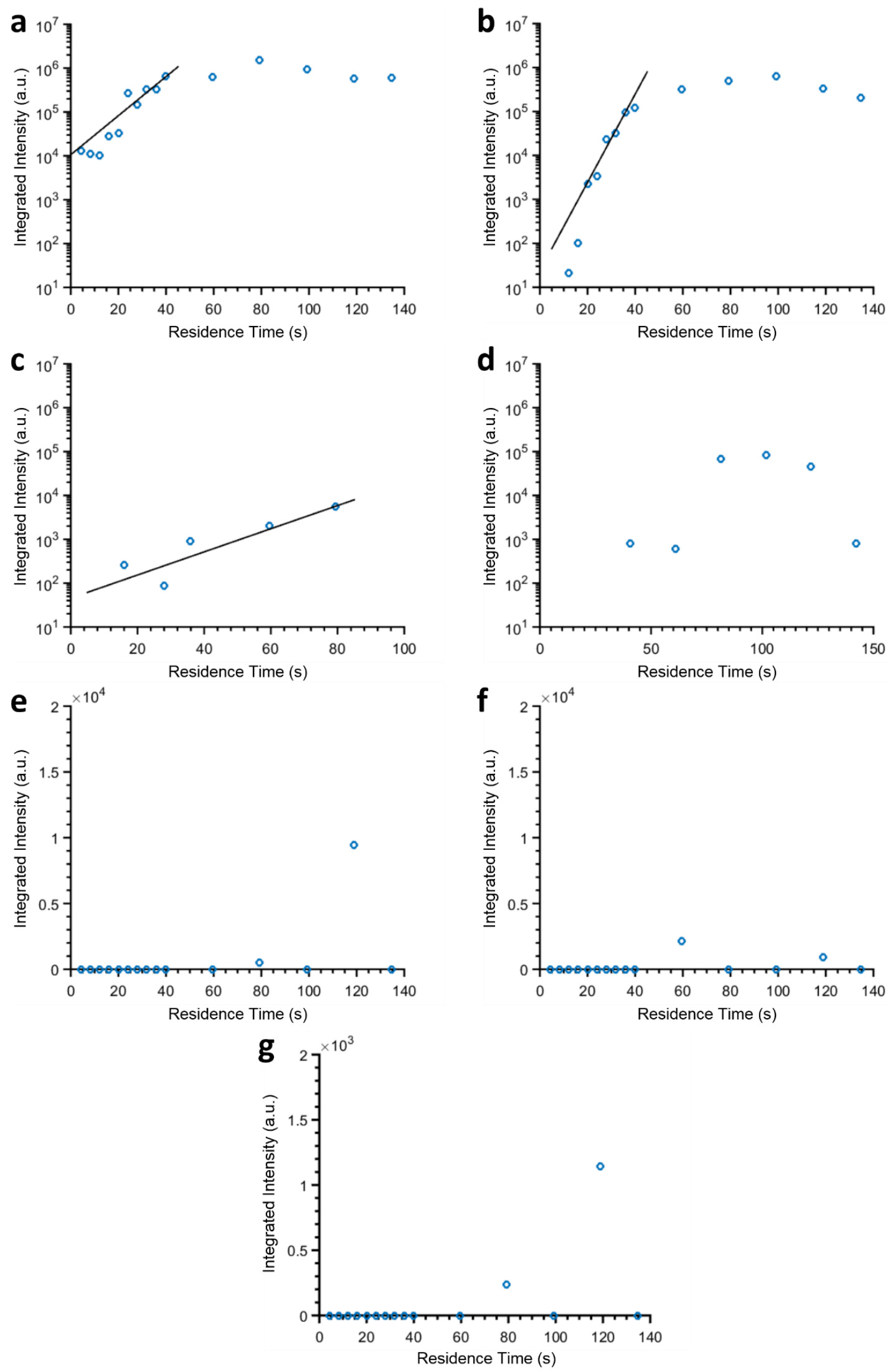

Figure S9: Integrated intensity semi-log plots of the diffraction patterns in Figure 6 and Supporting Figure 6 as a function of droplet residence time within the device. The tested nucleants were (a) calcite nanoparticles, (b) porous $58 \mathrm{~S}$ bioactive glass, (c) NX illite, (d) non- 


\section{WILEY-VCH}

porous 45S5 bioactive glass, (e) CPGs, (f) carboxylate-functionalized CPGs and (g) control. The diffraction intensity growth in (a) and (b) fits a first order exponential (black lines) then subsequently settles near a constant magnitude. Similarly, within the residence time of the device, the diffraction intensity from the NX illite run (c) fits an exponential (black line).

Clear diffraction signal growth is also observed due to 45S5 BG (d), but it is too inconsistent to fit to a trend. Very little diffraction could be observed in the CPG, carboxylatefunctionalized CPG and control runs, shown in normally-scaled plots (e, $\mathrm{f}$ and $\mathrm{g}$, respectively). A few random diffraction spots were seen and are attributed to device scaling.
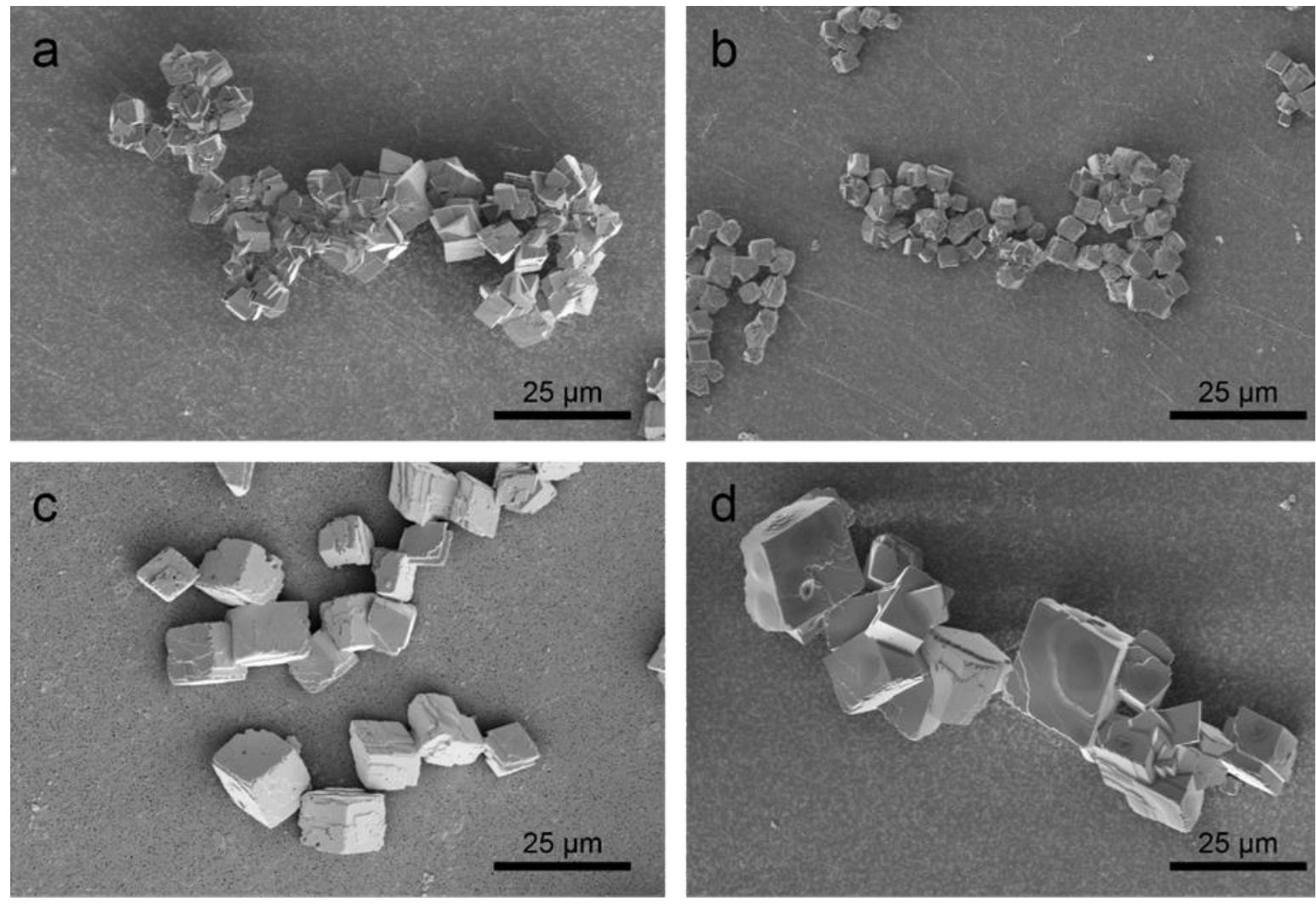

Figure S10: Sca experiments with $e$ non-porous $45 \mathrm{~S} 5$ Clusters of multi $\sim 2-5 \mu \mathrm{m}$. (c) Rou calcite crystals o of vaterite.
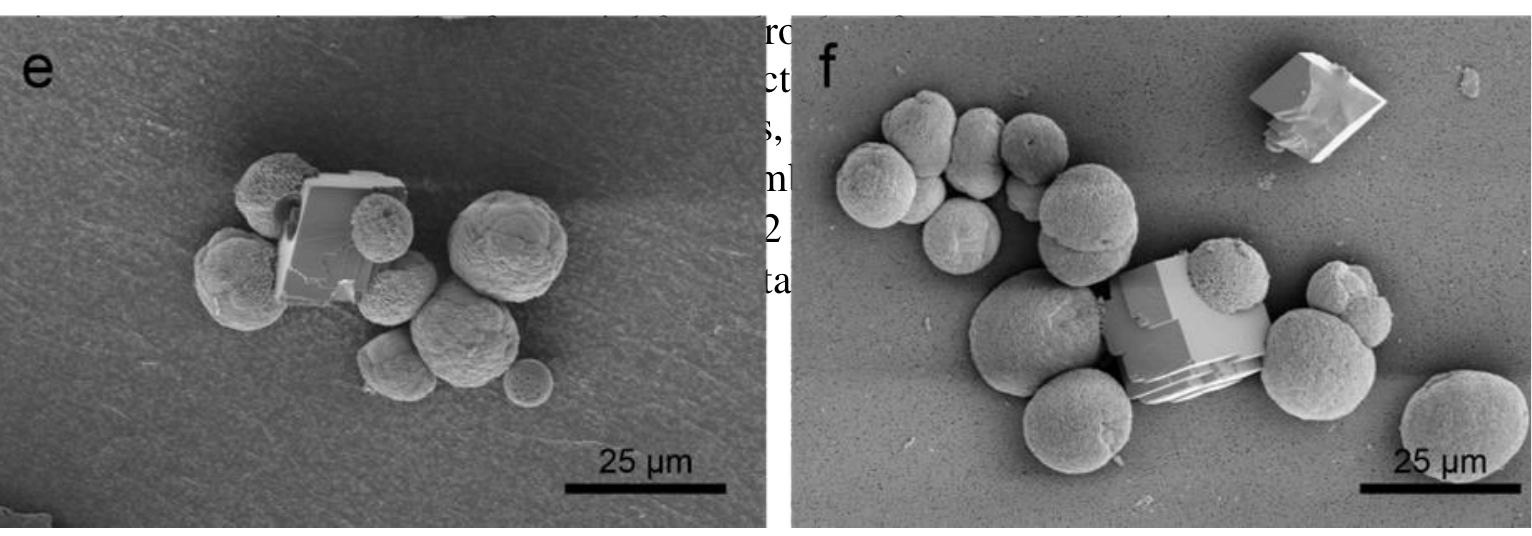

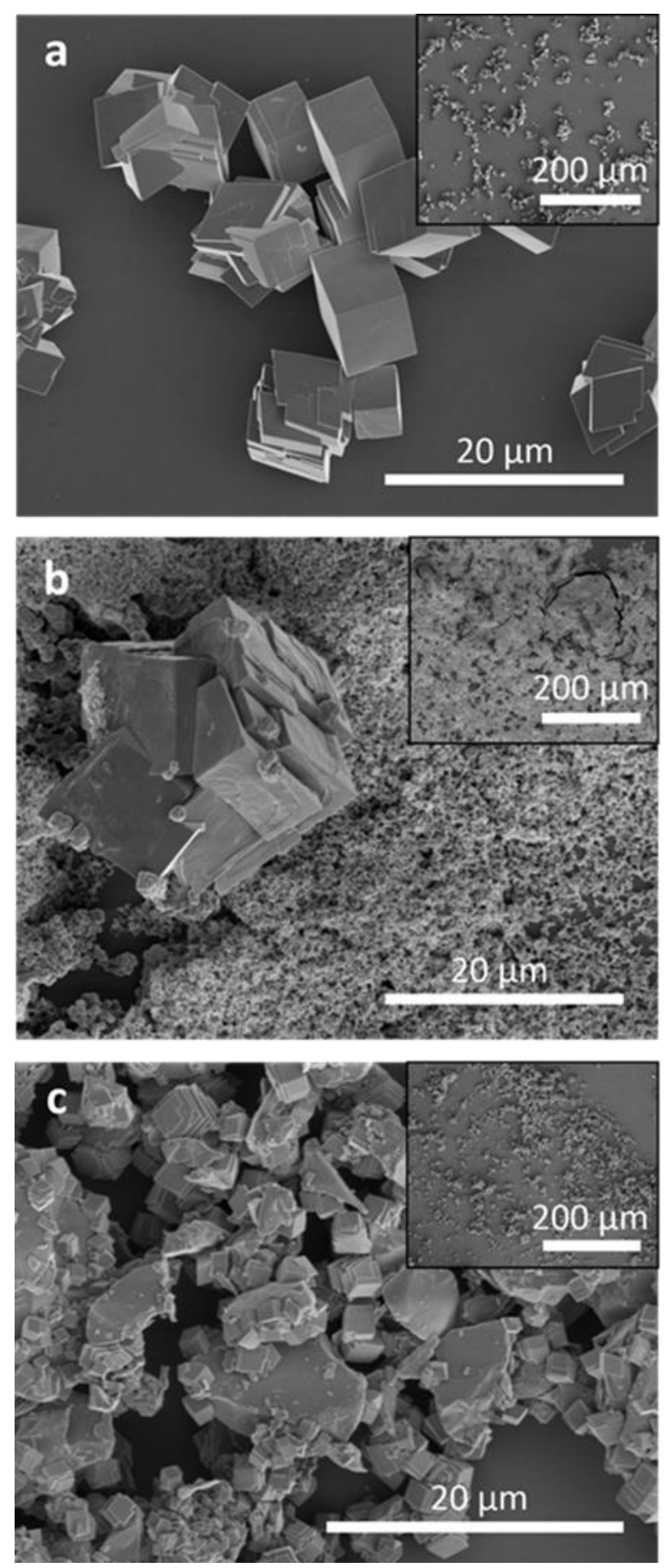

Supporting Figure S11: Scanning electron micrographs of $\mathrm{CaCO}_{3}$ precipitated in bulk after $10 \mathrm{~min}$ at $50 \mathrm{mM} \mathrm{Ca}{ }^{2+} / \mathrm{CO}_{3}{ }^{2-}$ concentration in the presence of (a) $0.005 \mathrm{wt} \%$ porous $58 \mathrm{~S}$ bioactive glass, (b) $0.005 \mathrm{wt} \%$ non-porous $45 \mathrm{~S} 5$ bioactive glass and (c) $0.89 \mathrm{wt} \%$ non-porous 45S5 bioactive glass to match the total surface area of $0.005 \mathrm{wt} \% 58 \mathrm{~S}$. (a) Only large rhombohedral calcite crystals are observed and no ACC remains. (b) Most material appears to be ACC though there are some large calcite crystals. (c) All ACC appears to have been depleted similar to (a), though a large amount of 45S5 bioactive glass is also observed due to its high concentration. 


\section{WILEY-VCH}
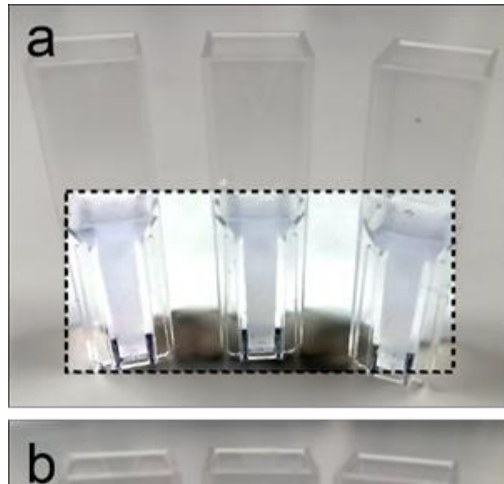

Figure S12: Pho crystals. (c) Turb bioactive glass sc As ACC is deple increases. Three
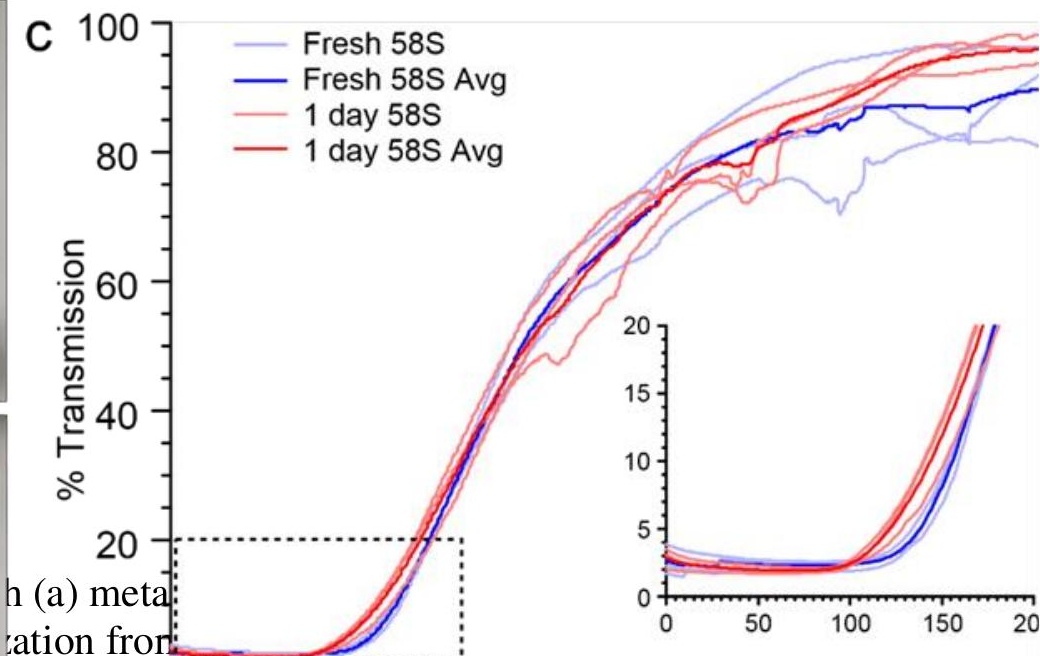

(1) I porous $58 \mathrm{~S}$ bioactive glásís solutions' (red)' ttom of the cuvette, light2Pansmisspoh $400 \quad 500$ age (darker) are shown for the freste a day old solutions, respectively, which indicate little difference between the two populations. The inset shows an enlargement of the region in the dotted black box.
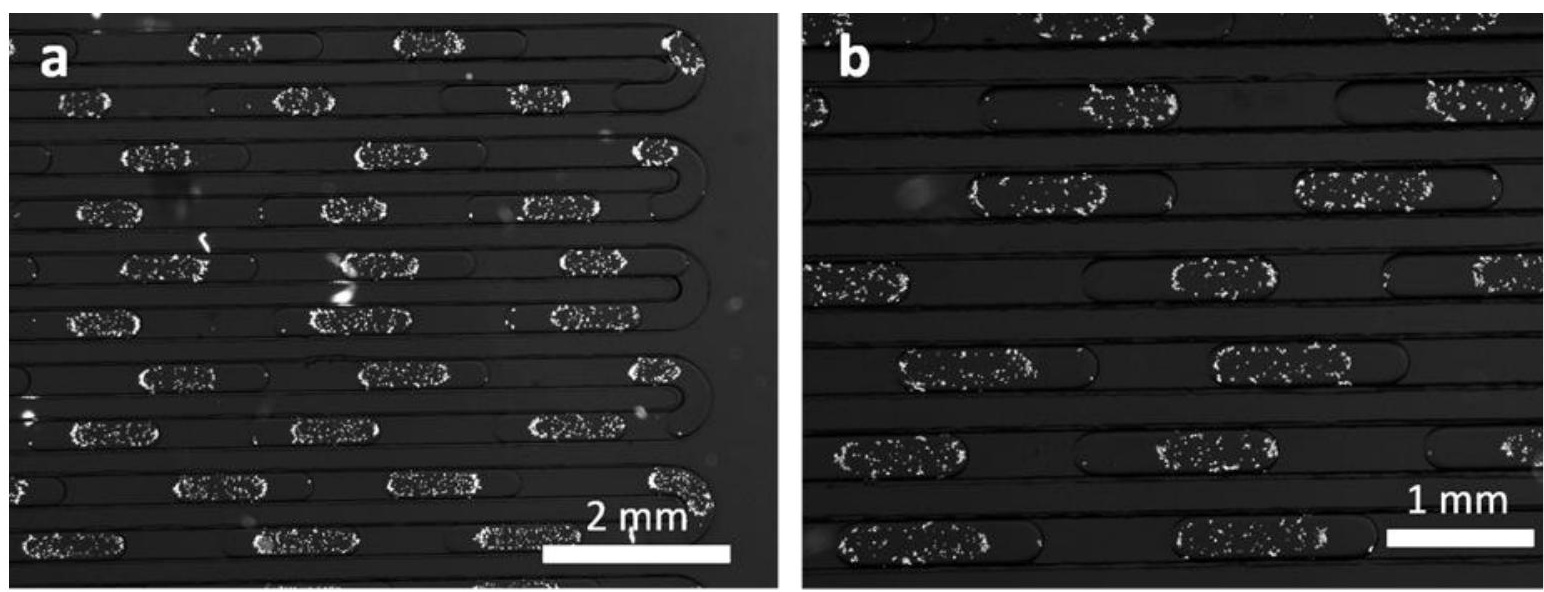

Figure S13: Opt
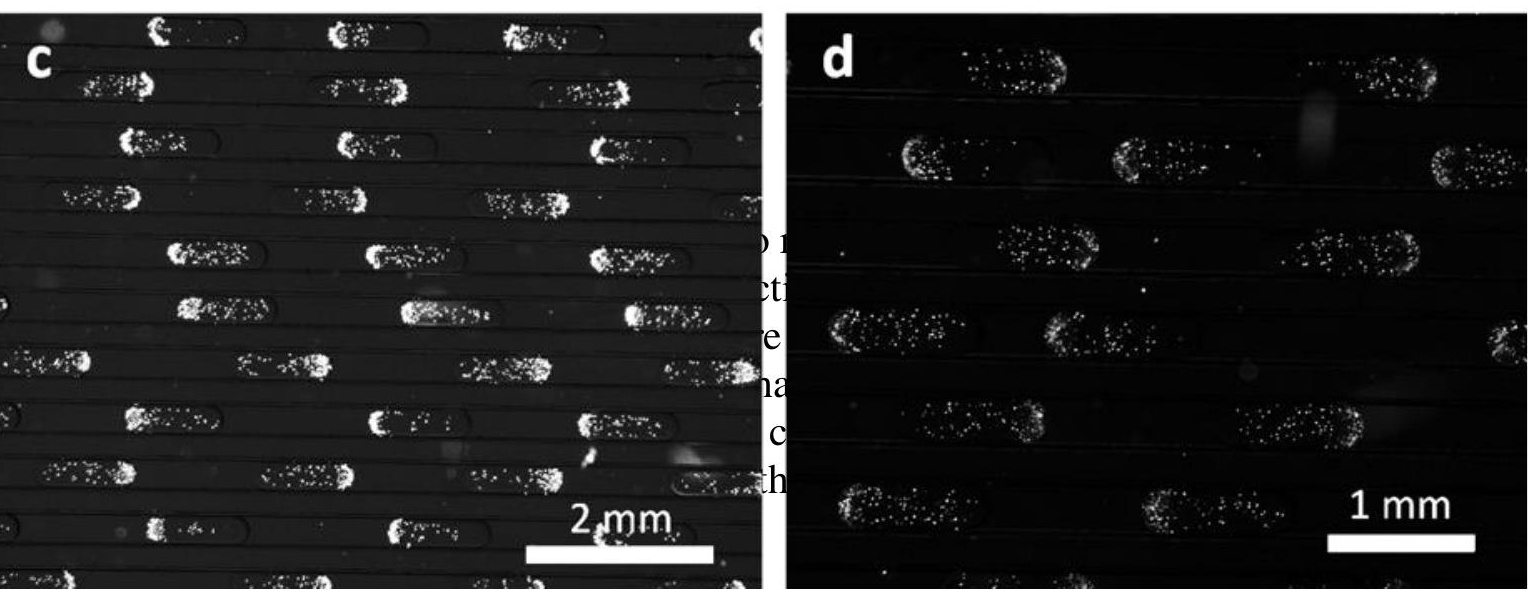